\title{
3-D microphysical model studies of Arctic denitrification: comparison with observations
}

\author{
S. Davies ${ }^{1}$, G. W. Mann ${ }^{1}$, K. S. Carslaw ${ }^{1}$, M. P. Chipperfield ${ }^{1}$, J. A. Kettleborough ${ }^{2}$, M. L. Santee ${ }^{3}$, H. Oelhaf ${ }^{4}$, \\ G. Wetzel ${ }^{4}$, Y. Sasano ${ }^{5}$, and T. Sugita ${ }^{5}$ \\ ${ }^{1}$ Institute for Atmospheric Science, School of Earth and Environment, University of Leeds, UK \\ ${ }^{2}$ Rutherford Appleton Laboratory, Didcot, Oxford, UK \\ ${ }^{3}$ Jet Propulsion Laboratory, Pasadena, California, USA \\ ${ }^{4}$ Institut für Meteorologie und Klimaforschung, Forschungszentrum Karlsruhe, Germany \\ ${ }^{5}$ National Institute for Environmental Studies, Ibaraki, Japan
}

Received: 5 November 2004 - Published in Atmos. Chem. Phys. Discuss.: 28 January 2005

Revised: 28 October 2005 - Accepted: 31 October 2005 - Published: 16 November 2005

\begin{abstract}
Simulations of Arctic denitrification using a 3D chemistry-microphysics transport model are compared with observations for the winters 1994/95, 1996/97 and 1999/2000. The model of Denitrification by Lagrangian Particle Sedimentation (DLAPSE) couples the full chemical scheme of the 3-D chemical transport model, SLIMCAT, with a nitric acid trihydrate (NAT) growth and sedimentation scheme. We use observations from the Microwave Limb Sounder (MLS) and Improved Limb Atmospheric Sounder (ILAS) satellite instruments, the balloon-borne Michelsen Interferometer for Passive Atmospheric Sounding (MIPASB), and the in situ $\mathrm{NO}_{\mathrm{y}}$ instrument on-board the ER-2. As well as directly comparing model results with observations, we also assess the extent to which these observations are able to validate the modelling approach taken. For instance, in $1999 / 2000$ the model captures the temporal development of denitrification observed by the ER-2 from late January into March. However, in this winter the vortex was already highly denitrified by late January so the observations do not provide a strong constraint on the modelled rate of denitrification. The model also reproduces the MLS observations of denitrification in early February 2000. In 1996/97 the model captures the timing and magnitude of denitrification as observed by ILAS, although the lack of observations north of $\sim 67^{\circ} \mathrm{N}$ in the beginning of February make it difficult to constrain the actual timing of onset. The comparison for this winter does not support previous conclusions that denitrification must be caused by an ice-mediated process. In 1994/95 the model notably underestimates the magnitude of denitrification observed during a single balloon flight of the MIPAS-B instru-
\end{abstract}

Correspondence to: S. Davies

(stewart@env.leeds.ac.uk) ment. Agreement between model and $\mathrm{MLS}^{\mathrm{HNO}} 3$ at $68 \mathrm{hPa}$ in mid-February 1995 is significantly better. Sensitivity tests show that a $1.5 \mathrm{~K}$ overall decrease in vortex temperatures, or a factor 4 increase in assumed NAT nucleation rates, produce the best statistical fit to MLS observations. Both adjustments would be required to bring the model into agreement with the MIPAS-B observations. The agreement between the model and observations suggests that a NAT-only denitrification scheme (without ice), which was discounted by previous studies, must now be considered as one mechanism for the observed Arctic denitrification. The timing of onset and the rate of denitrification remain poorly constrained by the available observations.

\section{Introduction}

Very large $\mathrm{NO}_{\mathrm{y}}$-containing particles at low number concentrations $\left(\sim 10^{-4} \mathrm{~cm}^{-3}\right)$ and extensive denitrification of the Arctic lower stratosphere were observed during the winter of 1999/2000 (Fahey et al., 2001; Northway et al., 2002; Santee et al., 2000). Less severe denitrification of the lower stratosphere has also been observed in previous cold Arctic winters (Arnold et al., 1989; Fahey et al., 1990; Wetzel et al., 1997; Sugita et al., 1998; Dessler et al., 1999; Waibel et al., 1999), although the lack of associated particle observations made it difficult to develop models of the denitrification process. The most thorough comparison of a denitrification model with observations so far (Waibel et al., 1999) was limited to a single balloon flight of the MIPAS-B instrument.

(C) 2005 Author(s). This work is licensed under a Creative Commons License. 
The extensive particle and denitrification observations in winter 1999/2000 have prompted a number of modelling studies aimed at quantifying the particle growth and denitrification processes. It has been shown that the large particles observed in January to March 2000 (Fahey et al., 2001; Northway et al., 2002) are unlikely to have been nucleated on synoptic-scale ice (Carslaw et al., 2002), as has been assumed in previous models of denitrification (Waibel et al., 1999; Kondo et al., 2000), although the role of mesoscale ice clouds remains uncertain. The simulations have also shown that NAT particles with concentrations as low as those observed can efficiently denitrify the Arctic lower stratosphere (Drdla et al., 2002; Mann et al., 2002, 2003). In previous studies (Carslaw et al., 2002; Mann et al., 2002, 2003) we have highlighted the importance of the dynamical state of the vortex for efficient denitrification by sedimentation of very low concentrations of particles. When NAT concentrations are very low, the particles must grow to large sizes in order to denitrify rapidly, so the particle growth process must be captured by a model, a factor that was ignored by Waibel et al. (1999).

The mechanisms of NAT-particle nucleation in the polar lower stratosphere remain uncertain, and this limits our ability to calculate denitrification in a model. There are three possibilities for NAT nucleation:

1. Tabazadeh et al. (2001) have suggested that homogeneous nucleation of NAT may occur at a rate sufficient to denitrify the Arctic stratosphere based on extrapolation of laboratory data by Salcedo et al. (2001). However, Knopf et al. (2002) have performed new laboratory measurements which indicate that homogeneous nucleation of NAT is too slow to form NAT PSCs, even at temperatures several $\mathrm{K}$ below $\mathrm{T}_{\mathrm{NAT}}$. Knopf et al. (2002) have also shown that the linear extrapolation of laboratory data to stratospheric conditions by Tabazadeh et al. (2001) gave physically unrealistic results under some conditions, and was likely to overestimate freezing rates. The general applicability of laboratory-measured homogeneous nucleation rates to the stratosphere has been called into question because of the potential role of surface contaminants (Tabazadeh et al., 2003). At present, the possibility of homogeneous nucleation of nitric acid hydrates remains an open and poorly quantified issue.

2. A second possibility involves NAT formation in mountain wave temperature perturbations (Deshler et al., 1994; Meilinger et al., 1995; Tsias et al., 1997). This process is supported by lidar observations which show that solid $\mathrm{HNO}_{3}$ particles can be produced downstream of mountain wave-induced ice clouds (Carslaw et al., 1998; Wirth et al., 1999; Hu et al., 2002; Fueglistaler et al., 2003). Large-scale model simulations have suggested that such a mechanism could produce a large amount of NAT in the Arctic (Carslaw et al., 1999). NAT PSCs downstream of wave clouds do not efficiently denitrify as the particles are small and have low sedimentation velocities. However, modelling studies by Dhaniyala et al. (2002) and Fueglistaler et al. (2002) have shown that the dense NAT clouds produced downwind of mountain wave ice PSCs may subsequently act as sources for large NAT particles at low number concentrations throughout cold regions of the vortex by gradual sedimentation into the underlying NATsupersaturated air. Mann et al. (2005) have explored the vortex-wide influence of such a mechanism and suggest that it may play a significant role in large NAT particle production and denitrification in the Arctic. However, methods of including such processes in largescale models have not yet been developed. However, several other studies have concluded that a significant proportion of observed PSCs cannot be explained by mesoscale ice-formation but by synoptic scale temperature changes (Spang et al., 2001; Saitoh et al., 2002; Fromm et al., 2003; Pagan et al., 2004).

3. The third possibility involves heterogeneous nucleation of NAT on the surface of a variety of stratospheric constituents other than ice. Potential nuclei include meteoritic debris and ion clusters (Yu, 2004). Supporting evidence for the efficiency of such a mechanism is indicated by Drdla et al. (2002) where a particle freezing mechanism operating above the ice frost point best matched the observed denitrification.

None of these mechanisms is sufficiently well constrained by observations and physical models to allow for an accurate winter-long simulation of denitrification. One aim of this study is to test a model of denitrification that assumes a simplified NAT formation mechanism to see whether observations could help to constrain how the denitrification process should be treated in large-scale models. The NAT nucleation scheme that we use assumes that NAT particles form at a constant rate in all air below the NAT temperature. This scheme produces NAT particle fields that agree reasonably well with observations in the period January-March 2000 (Carslaw et al., 2002). We show below that this scheme also captures much of the variation in observed denitrification, but where there are discrepancies between observed and modelled denitrification there are insufficient observations to constrain improvements to the model.

This study is an extension of our previous simulations of the particles (Carslaw et al., 2002) and denitrification (Mann et al., 2002, 2003). In those studies we simulated the particle growth and sedimentation including the feedback of changes in the $\mathrm{HNO}_{3}$ field on particle behaviour, but we did not couple the denitrification model to the full chemical evolution of the Arctic winter vortex. In this study, we include that coupling because $\mathrm{NO}_{y}$ partitioning is important when comparing with observations of $\mathrm{HNO}_{3}$ and $\mathrm{NO}_{\mathrm{y}}$ species. 


\section{Model description}

The DLAPSE model used for this study is a Lagrangian microphysical NAT-particle model coupled to a full-chemistry version of the SLIMCAT CTM (Chipperfield, 1999). DLAPSE calculates the time-dependent growth, advection and sedimentation of NAT particles and has been described in detail in Carslaw et al. (2002). Changes in gas-phase $\mathrm{HNO}_{3}$ mass due to NAT-particle growth and sedimentation are calculated by DLAPSE and applied to the SLIMCAT Eulerian grid, which is then advected with all the other gas phase species. Both DLAPSE and SLIMCAT are forced using operational analyses from the European Centre for Medium-Range Weather Forecasts (ECMWF). Figure 1 shows a schematic representation of the coupled model.

For this study, the SLIMCAT resolution was $2.8^{\circ}$ longitude $\times 2.8^{\circ}$ latitude $\times 36$ isentropic levels. In the lower stratosphere, the model isentropic levels were spaced at $10 \mathrm{~K}$ potential temperature intervals, corresponding to a vertical resolution of around $400 \mathrm{~m}$. The SLIMCAT stratospheric chemistry scheme contains 41 species and 120 chemical reactions, including heterogeneous reactions, using data from Sander et al. (2000). This model is an improvement on that used in Mann et al. (2002) as it includes time-dependent partitioning of $\mathrm{NO}_{\mathrm{y}}$ between its constituent components:

$$
\begin{aligned}
\mathrm{NO}_{\mathrm{y}} & =\mathrm{N}+\mathrm{NO}+\mathrm{NO}_{2}+\mathrm{NO}_{3}+2 \mathrm{~N}_{2} \mathrm{O}_{5}+\mathrm{HNO}_{3} \\
& +\mathrm{HNO}_{4}+\mathrm{ClONO}_{2}+\mathrm{BrONO}_{2}
\end{aligned}
$$

Heterogeneous reactions are assumed to occur only on the surface of liquid aerosols, which dominate the particle surface area in these simulations. The surface area of liquid aerosols is determined assuming there are 10 particles $\mathrm{cm}^{-3}$ and $\mathrm{HNO}_{3}$ uptake in thermodynamic equilibrium according to Carslaw et al. (1995). The liquid aerosols are assumed to have a log-normal size distribution with a width $(\sigma)=1.8$. Uptake of $\mathrm{HNO}_{3}$ into the liquid aerosol reduces gas-phase $\mathrm{HNO}_{3}$, thereby slowing the rate of NAT particle growth. Sequestration of $\mathrm{HNO}_{3}$ in liquid aerosols is assumed to dominate competition for gas phase $\mathrm{HNO}_{3}$ and only the residual gas-phase $\mathrm{HNO}_{3}$ is available for NAT growth in any one time step.

Initial $\mathrm{NO}_{\mathrm{y}}$ fields are taken from output from SLIMCAT multi-annual runs and scaled to match available observations in each winter. The precise initialisation method was dependent on the data available for each winter. Further details of model initialisation for each winter are given below. Other model tracers were not scaled.

In our previous studies we took a pragmatic approach to specifying the NAT nucleation rate: NAT was assumed to nucleate at a constant rate wherever $\mathrm{T}<\mathrm{T}_{\mathrm{NAT}}$. We use the same approach and the same nucleation rate $\left(8.0 \times 10^{-10} \mathrm{~cm}^{-3} \mathrm{~s}^{-1}\right)$ in this study. The extent to which the observations provide a constraint on the model nucleation scheme is explored in this paper. The volume-averaged nucleation rate used in DLAPSE was derived from a compari-

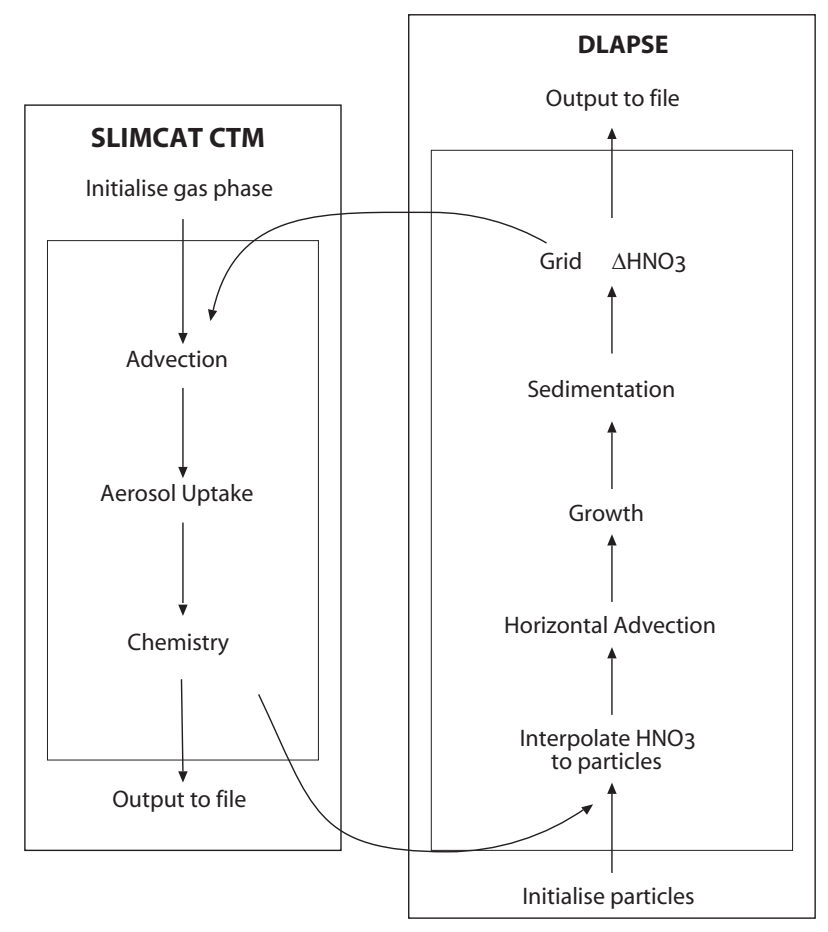

Fig. 1. Flow diagram illustrating the coupled DLAPSE/SLIMCAT model.

son of our model and ER-2 NAT-particle observations on 20 January 2000 (Fahey et al., 2001; Northway et al., 2002). Integrated number densities from the forward inlet on the $\mathrm{NO}_{\mathrm{y}}$ instrument were approximately $10^{-4} \mathrm{~cm}^{-3}$ for particles greater than $5 \mu \mathrm{m}$ diameter for the period $45 \mathrm{ks}-47 \mathrm{ks}$ UT during this flight (Northway et al., 2002). A series of model runs was carried out with the nucleation rate adjusted each time to produce model particle number densities of $\sim 10^{-4} \mathrm{~cm}^{-3}$ in a sampling volume corresponding to the grid boxes containing the ER-2 flight track (latitude: $69.3^{\circ} \mathrm{N}$ to $85.6^{\circ} \mathrm{N}$, longitude: $16.9^{\circ} \mathrm{E}$ to $22.5^{\circ} \mathrm{E}$ and altitude: $420 \mathrm{~K}$ to $440 \mathrm{~K}$ ).

In the following sections, model simulations are compared with observations of denitrification in three Arctic winters 1999/2000, 1996/97 and 1994/95. All simulations were run for a period of 100 days from early winter prior to the onset of temperatures below $\mathrm{T}_{\mathrm{NAT}}$. In each case, a full-chemistry control run without denitrification was performed to provide a "passive" $\mathrm{NO}_{\mathrm{y}}$. All of the winters studied were colder than the climatological average for the Arctic over the period 1965-1998 and had extended periods of temperatures below $T_{\text {NAT }}$ (Pawson and Naujokat, 1999). Although each of the winters was cold, considerable dynamical differences exist between them. 

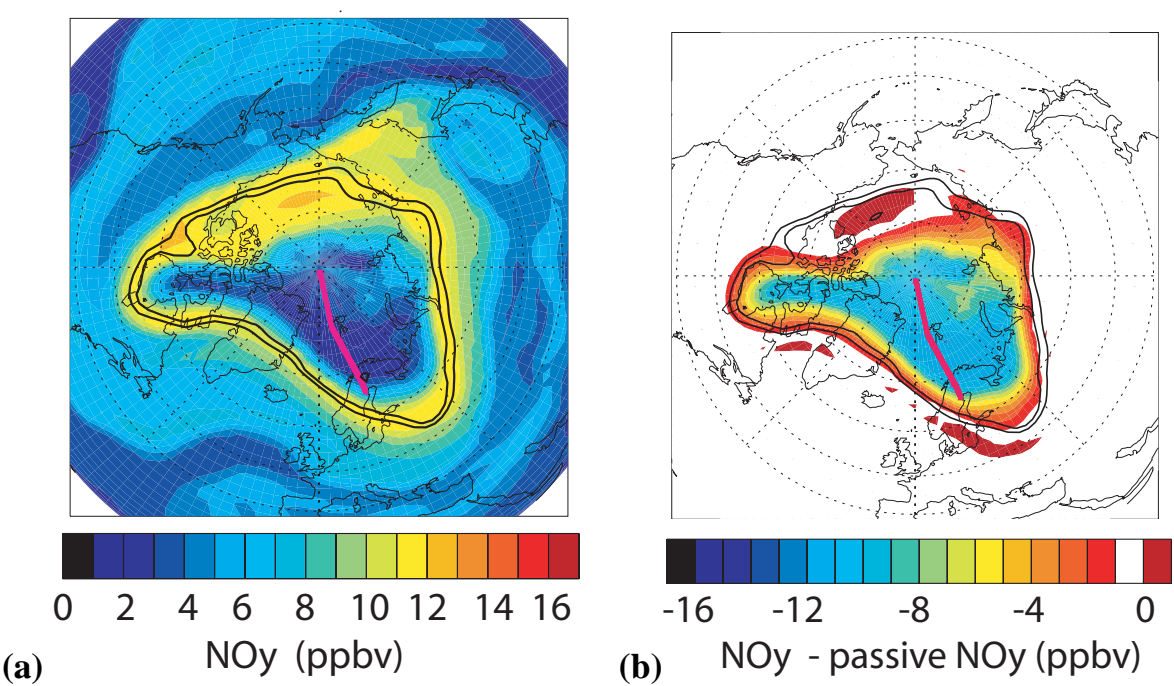

Fig. 2. Model (a) $\mathrm{NO}_{\mathrm{y}}$ and (b) $\mathrm{NO}_{\mathrm{y}}$ - passive $\mathrm{NO}_{\mathrm{y}}$ at $465 \mathrm{~K}$ on 20 January 2000 . Black contours indicate the 32 and $36 \times 10^{-6} \mathrm{~m}^{2} \mathrm{~K} \mathrm{~s}^{-1} \mathrm{~kg}^{-1}$ (PVU) Modified Potential Vorticity (MPV) contours from the ECMWF analyses. The ER-2 flight track is shown in red.

\section{Comparison with observations}

\subsection{Winter 1999/2000}

The Arctic winter of 1999/2000 was characterised by an exceptionally cold vortex that was for long periods concentric with the area below $\mathrm{T}_{\mathrm{NAT}}$ between mid-December 1999 and late-January 2000, producing ideal conditions for denitrification. Our previous simulations without coupled chemistry (Mann et al., 2003) suggested that the vortex-mean denitrification reached a peak $>60 \%$ by early-February 2000 between 440 and $520 \mathrm{~K}$, and more than $40 \%$ denitrified between 550 and $380 \mathrm{~K}$ at this time. Model $\mathrm{NO}_{\mathrm{y}}$ was initialised from a full-chemistry, multi-annual SLIMCAT model run. SLIMCAT $\mathrm{NO}_{\mathrm{y}}$ was scaled to observations from the in-vortex JPL Mark IV interferometer balloon flight on 3 December 1999 (Toon et al., 1992) in order to constrain model $\mathrm{NO}_{\mathrm{y}}$ species inside the polar vortex whilst preserving partitioning between constituent species. No other model tracers were scaled by observations.

\subsubsection{Comparison with the airborne in-situ $\mathrm{NO}_{\mathrm{y}}$ instrument}

Figure 2 shows the modelled $\mathrm{NO}_{\mathrm{y}}$ and denitrification at $465 \mathrm{~K}$ on January 20, 2000. Also shown is the flightpath of the ER-2, the first in-vortex flight of the winter. The model predicts very low $\mathrm{NO}_{\mathrm{y}}(\sim 2 \mathrm{ppbv})$ due to extensive denitrification (up to $10 \mathrm{ppbv}$ ) at these altitudes. Modelled denitrification was essentially complete by this time, having occurred most strongly between mid-December and midJanuary (Mann et al., 2003).

Figure 3 shows the modelled and observed $\mathrm{NO}_{\mathrm{y}}$, model passive $\mathrm{NO}_{\mathrm{y}}$ and observed $\mathrm{NO}_{\mathrm{y}}^{*}$ along the ER-2 flight track on this day. Observed $\mathrm{NO}_{\mathrm{y}}^{*}$ is derived from ARGUS $\mathrm{N}_{2} \mathrm{O}$
(Jost et al., 1998) using the relationship derived by Popp et al. (2001):

$\mathrm{NO}_{\mathrm{y}}^{*}=17.0959-0.0204635\left[\mathrm{~N}_{2} \mathrm{O}\right]-0.000105\left[\mathrm{~N}_{2} \mathrm{O}\right]^{2}$

It is important to note that the inlet of the $\mathrm{NO}_{\mathrm{y}}$ instrument onboard the ER-2 allows size-dependent aerodynamic enhancement of aerosol particles up to $\sim 5 \mu \mathrm{m}$ diameter. Therefore, in the presence of $\mathrm{NO}_{\mathrm{y}}$-containing aerosol, measured $\mathrm{NO}_{\mathrm{y}}$ is susceptible to enhancement by condensed phases and should be considered an upper limit (Northway et al., 2002). Modelled $\mathrm{NO}_{\mathrm{y}}$ includes $\mathrm{HNO}_{3}$ condensed in ternary aerosol but does not include NAT-phase $\mathrm{HNO}_{3}$ as the particles are generally large and present at low numbers.

There are differences of up to $3 \mathrm{ppbv}$ between observed $\mathrm{NO}_{\mathrm{y}}^{*}$ and model passive $\mathrm{NO}_{\mathrm{y}}$ for the majority of this flight. This discrepancy cannot be attributed to spatial inhomogeneity in the model tracer field as the range of model passive $\mathrm{NO}_{\mathrm{y}}$ is narrow (as indicated by the shaded region: see figure caption). It is more likely that this offset is due to the inherent limitations of using an initial NOy field from a SLIMCAT multi-annual run, re-scaled to match a single in-vortex balloon flight. Uncertainties in the model transport over a period of $\sim 2$ months must also contribute. Model and observed $\mathrm{N}_{2} \mathrm{O}$ (not shown) are in good agreement for the outward leg of the flight (between 37-45 ks UT) but the model underestimates observed $\mathrm{N}_{2} \mathrm{O}$ by $\sim 20$ ppbv $(\sim 15 \%)$ at higher altitude during the homeward leg (51-61 ks UT).

The model reproduces the large spikes in observed $\mathrm{NO}_{\mathrm{y}}$ which are associated with ascent and descent through thin layers of strongly renitrified air around $15 \mathrm{~km}$. The model also reproduces the very low $\mathrm{NO}_{\mathrm{y}}$ values of around $2 \mathrm{ppbv}$ at $52 \mathrm{ks}$ UT when the aircraft was at $20 \mathrm{~km}$ altitude near the pole. The model does not reproduce several of the smaller- 


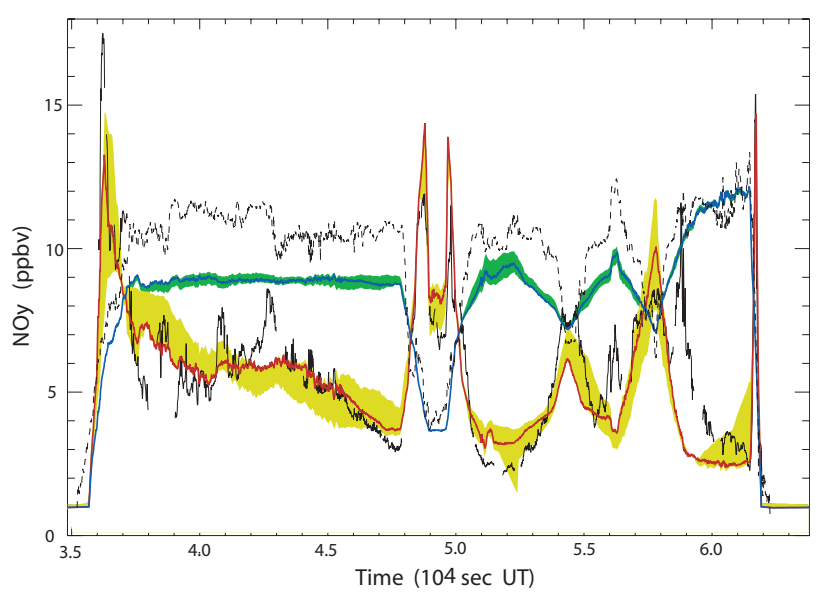

Fig. 3. Comparison between ER-2 observed $\mathrm{NO}_{\mathrm{y}}$ (black line) and DLAPSE/SLIMCAT $\mathrm{NO}_{\mathrm{y}}$ (red line) spatially and temporally interpolated to the flight track on 20 January 2000. Also shown are observed $\mathrm{NO}_{\mathrm{y}}^{*}$ (dashed line) and model passive $\mathrm{NO}_{\mathrm{y}}$ (blue). Yellow and green shading indicates the range of model $\mathrm{NO}_{\mathrm{y}}$ and passive $\mathrm{NO}_{\mathrm{y}}$ respectively when the model is sampled $+/-2.5^{\circ}$ about the flight track.

scale features in observed $\mathrm{NO}_{\mathrm{y}}$ on this flight, as found between $40-45 \mathrm{ks}$ UT and between $55-60 \mathrm{ks}$ UT. Figure 4 shows the model $\mathrm{NO}_{\mathrm{y}}$ profile along the ER-2 flight track on 20 January 2000. Strong modelled denitrification extends from $570 \mathrm{~K}$ to $\sim 440 \mathrm{~K}$ with a narrow renitrified layer immediately below. The model predicts very low $\mathrm{NO}_{\mathrm{y}}(<2 \mathrm{ppbv})$ in a layer from $\sim 520-\sim 450 \mathrm{~K}$, just above the ER-2 on this day.

Figure 5 shows the modelled $\mathrm{NO}_{\mathrm{y}}$ and denitrification at $465 \mathrm{~K}$ on 11 March 2000. Vortex temperatures had risen above the NAT temperature by this time, although a large proportion of the vortex remained extensively denitrified. The increase in apparent denitrification at this isentropic level in the model (up to $13 \mathrm{ppb}$ ) is due to descent of very denitrified air from higher altitudes rather than ongoing denitrification in the model (Fig. 4). On this day, the ER-2 sampled both the vortex-core and mid-latitude air. Figure 6 shows that on 11 March the model passive $\mathrm{NO}_{\mathrm{y}}$ overestimates observed $\mathrm{NO}_{\mathrm{y}}^{*}$ in the core of the vortex at $460 \mathrm{~K}(50-$ $55 \mathrm{ks} U \mathrm{~T})$ by $\sim 2$ ppbv. At lower altitude, observed $\mathrm{NO}_{\mathrm{y}}^{*}$ is underestimated by a similar amount (30-33 ks UT). Close to the vortex edge (33-35 ks UT and 42-45 ks UT), both model and observed passive tracers are characterised by increased variability although the model does not fully capture the many small-scale features in observed $\mathrm{NO}_{\mathrm{y}}^{*}$. The DLAPSE model does reproduce the low $\mathrm{NO}_{\mathrm{y}}$ in the core of the vortex and the sharp $\mathrm{NO}_{\mathrm{y}}$ gradient at the edge of the vortex.

Figure 7 shows a probability density plot of all ER-2 observations of $\mathrm{NO}_{\mathrm{y}}-\mathrm{NO}_{\mathrm{y}}^{*}$ where ambient temperatures were above $\mathrm{T}_{\mathrm{NAT}}$ for January-March 2000 as contour lines. Modelled $\mathrm{NO}_{\mathrm{y}}$-passive $\mathrm{NO}_{\mathrm{y}}$ was interpolated to the location and

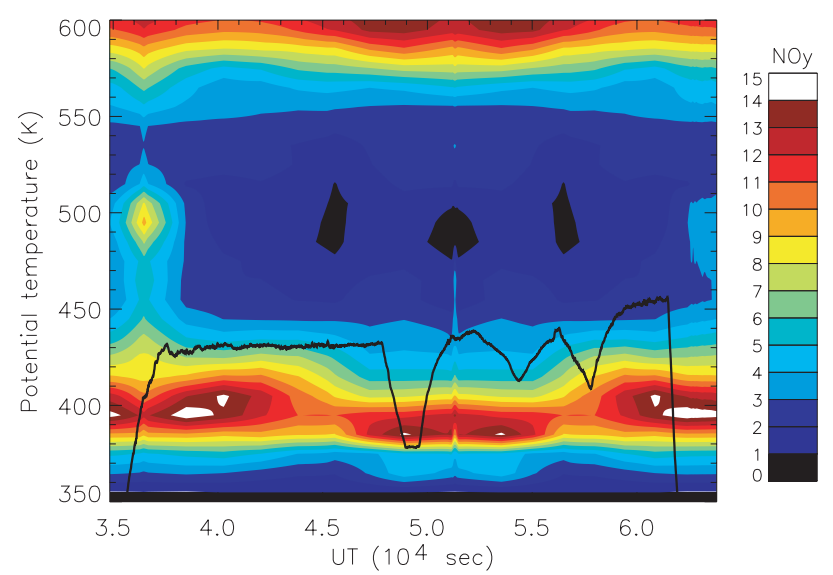

Fig. 4. Contour plot showing the DLAPSE/SLIMCAT NO $\mathrm{NO}_{\mathrm{y}}$ profile (ppbv) as a function of potential temperature and time along the ER-2 flight track for 20 January 2000. The potential temperature of ER-2 aircraft is also shown (black line).

time of the observations and is shown as the filled contours. Data were grouped in $10 \mathrm{~K} \times 1 \mathrm{ppbv}$ bins. This approach excludes possible contributions from enhancements in the observed $\mathrm{NO}_{\mathrm{y}}$ due to sampling of small particles. The peak observed denitrification occurs at $460 \mathrm{~K}(\sim 12 \mathrm{ppbv})$ and accounts for $\sim 90 \%$ of available $\mathrm{NO}_{\mathrm{y}}$ at this altitude. The duration of aircraft encounters with nitrified airmasses was short, hence the absence of a significant signal of nitrification in Fig. 7. The $\sim 1$ ppbv observed nitrification between 460 and $475 \mathrm{~K}$ is most likely due to the limitations of the $\mathrm{NO}_{\mathrm{y}}^{*}$ relationship in extra-vortex air rather than consistent weak nitrification in observations.

The model overestimates the magnitude of observed denitrification by $\sim 1 \mathrm{ppbv}$ at $460 \mathrm{~K}$ but underestimates the magnitude of denitrification by $\sim 2$ ppbv at $435 \mathrm{~K}$. This difference is of similar magnitude to the uncertainty in modelled passive $\mathrm{NO}_{\mathrm{y}}$ which tends to be higher than observed $\mathrm{NO}_{\mathrm{y}}^{*}$ at the highest altitudes, especially in spring (as indicated in Fig. 6). At lower altitudes and earlier in the winter, the model passive $\mathrm{NO}_{\mathrm{y}}$ tends to underestimate observed $\mathrm{NO}_{\mathrm{y}}^{*}$ (Fig. 3), indicating that the model may have a larger vertical $\mathrm{NO}_{\mathrm{y}}$ gradient in the polar vortex than is observed. It is also likely that the fixed NAT nucleation rate in the model is not representative of the real atmosphere throughout the winter. The NAT nucleation rate has been scaled to match NAT concentrations observed by the ER-2 in January at 420-440 K. If NAT nucleation rates were significantly different in December and early January when observations are not available, then discrepancies between model and observed denitrification will occur. Additional contributions to denitrification in the real atmosphere from other processes which are not represented in the model may also contribute to the discrepancy between observed and modelled denitrification. Observations of NAT and denitrification that begin in late January cannot really address this issue. 


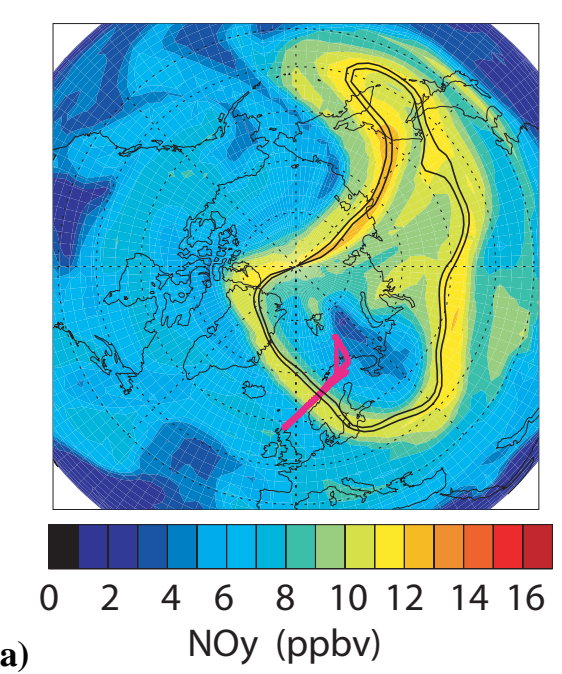

(a)

NOy (ppbv)

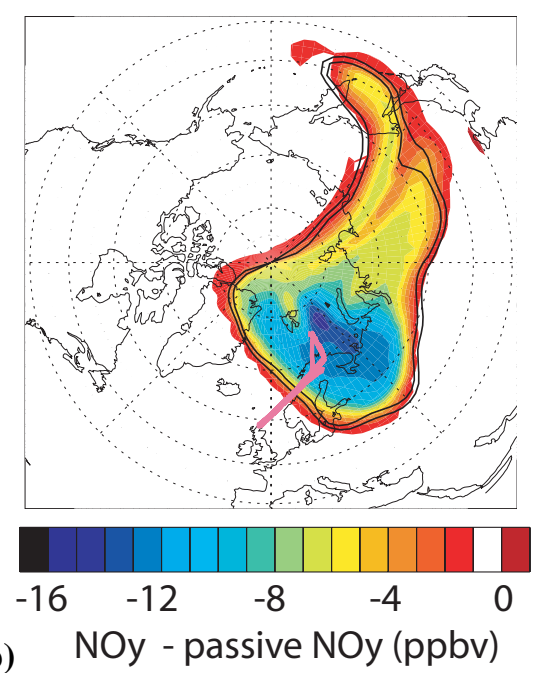

(b) NOy - passive NOy (ppbv)

Fig. 5. As Fig. 2, but for 11 March 2000. The ER-2 flight track is shown in red.

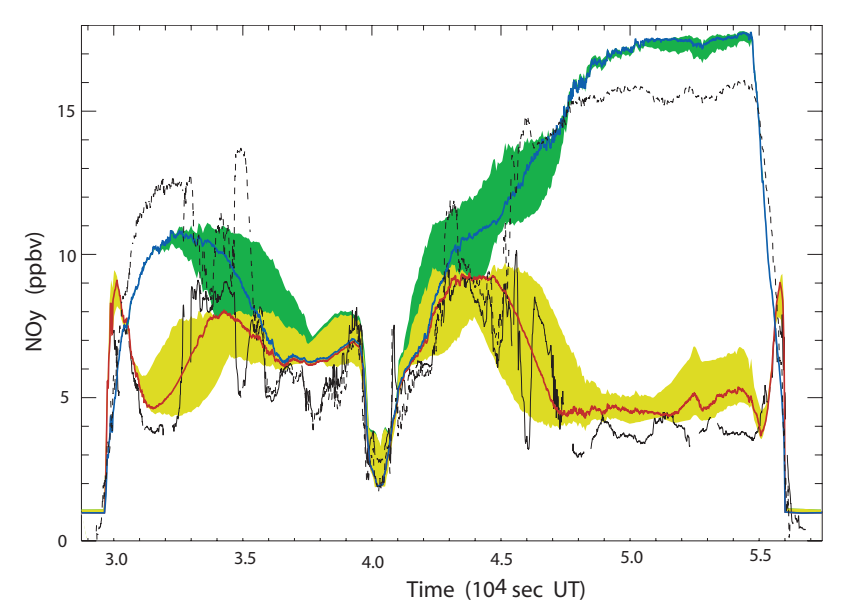

Fig. 6. As Fig. 3, but for the ER-2 flight on 11 March 2000.

A simpler thermodynamic equilibrium NAT-based denitrification scheme has previously been used to simulate this winter (Davies et al., 2002). Condensed $\mathrm{HNO}_{3}$ was partitioned between a small non-sedimenting particle mode and a large particle mode with a fall velocity corresponding to a particle radius of $6.5 \mu \mathrm{m}$. Although this simple scheme was able to capture the magnitude of denitrification in the core of the vortex, it was unable to reproduce the sharp gradients in denitrification observed close to the edge of the vortex. The tendency for thermodynamic equilibrium schemes to "smear out" denitrification has also been demonstrated in an idealised study by Mann et al. (2002). Under conditions where the vortex meteorology is favourable for denitrification over a prolonged period, as in 1999/2000, residual $\mathrm{NO}_{\mathrm{y}}$ may approach thermodynamic equilibrium values in the core of the vortex. Thus, the observations of widespread and se-

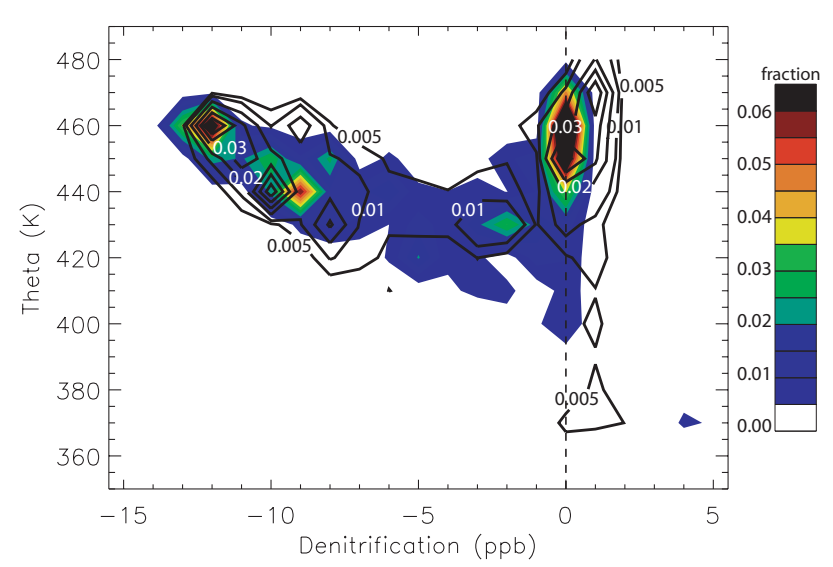

Fig. 7. Probability density plot for all ER-2 $\mathrm{NO}_{\mathrm{y}}$ observations at temperatures above $\mathrm{T}_{\mathrm{NAT}}$ during the SOLVE/THESEO-2000 campaign. Black line contours show the distribution of ER-2 $\mathrm{NO}_{\mathrm{y}}-\mathrm{NO}_{\mathrm{y}}^{*}$ and filled contours show the corresponding model distribution of interpolated $\mathrm{NO}_{\mathrm{y}}$-passive $\mathrm{NO}_{\mathrm{y}}$.

vere denitrification in 1999/2000 alone, do not unambiguously constrain model denitrification schemes.

\subsubsection{Comparison with MLS}

The Microwave Limb Sounder (MLS) instrument on-board the Upper Atmosphere Research Satellite (UARS) has provided global observations of many key stratospheric species, including $\mathrm{O}_{3}, \mathrm{HNO}_{3}$ and $\mathrm{ClO}$ since its launch in 1991 (Waters et al., 1999). In recent years, MLS operation has been severely curtailed, although it did make gas-phase $\mathrm{HNO}_{3}$ measurements over a restricted region of the Arctic in two periods during 1999/2000 (Santee et al., 2000). 
(a)

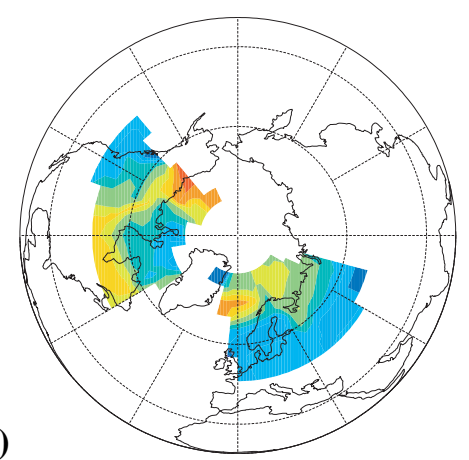

(b)

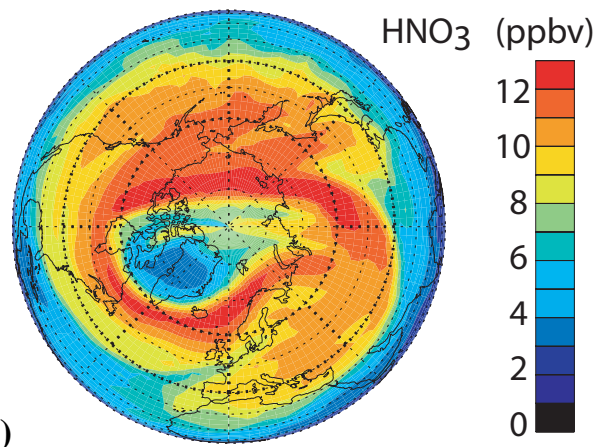

Fig. 8. Comparison of (a) composite MLS Version 5 observed $\mathrm{HNO}_{3}$ at $68 \mathrm{hPa}$ on 9-11 February 2000 with (b) DLAPSE/SLIMCAT HNO 3 interpolated to $68 \mathrm{hPa}$ and degraded to MLS vertical resolution at 12:00 UT on 10 February 2000.

In order to compare the model with the satellite observations, the model fields were interpolated from isentropic levels to the standard pressure coordinates of MLS. The model fields were further modified by the application of the MLS averaging kernel to degrade the model fields to the vertical resolution of the MLS instrument. No horizontal interpolation of the model was performed.

Observations of gas phase $\mathrm{HNO}_{3}$ at $68 \mathrm{hPa}$ on 9-11 February, 2000 from Version 5 MLS (Fig. 8a) indicate a region with low $\mathrm{HNO}_{3}(\sim 4-5 \mathrm{ppbv})$ in the polar vortex over Greenland and Baffin Island. The satellite observations also indicate a region with high $\mathrm{HNO}_{3}$ mixing ratios $(\sim 11 \mathrm{ppbv})$ located over the Alaska/Yukon coastline. Figs. 8b shows the model $\mathrm{HNO}_{3}$ interpolated to $68 \mathrm{hPa}$ after the application of the MLS averaging kernel on 10 February 2000. Degrading the vertical resolution of the model increases the apparent gas-phase $\mathrm{HNO}_{3}$ by $2-4 \mathrm{ppbv}$ in non-denitrified polar vortex air and reduces apparent gas-phase $\mathrm{HNO}_{3}$ by a similar amount in strongly denitrified regions of the vortex. These changes are due to the contribution of higher altitudes in the kernel smoothing.

The degraded model field reproduces the overall magnitude and location of the observed high $\mathrm{HNO}_{3}$ over the Alaskan coastline and the reduced $\mathrm{HNO}_{3}$ over Greenland. Significant model overestimates of MLS observed $\mathrm{NO}_{\mathrm{y}}$ in mid-latitude air masses over the Baltic Sea and the coast of the western USA are most likely attributable to inaccurate initialisation of model $\mathrm{HNO}_{3}$ at higher altitudes in the extravortex region. In-vortex $\mathrm{NO}_{\mathrm{y}}$ comparisons are unlikely to be significantly affected by the error in mid-latitude initialisation as studies have indicated that cross-vortex mixing was weak during the period of this study (Greenblatt et al., 2002).

In summary, the limited availability of high-resolution tracer observations in polar regions is a significant limitation for the initialisation of 3-D chemical models in this winter. These results indicate that although the DLAPSE/SLIMCAT model is able to reproduce the observed $\mathrm{NO}_{\mathrm{y}}$, quantitative diagnosis of model denitrification also requires accurate ini- tialisation of passive $\mathrm{NO}_{\mathrm{y}}$ and its subsequent transport. Despite these caveats, the microphysical denitrification scheme results in an improved representation of denitrification, particularly close to the edge of the polar vortex, where equivalent equilibrium denitrification schemes are often unable to reproduce the gradient in $\mathrm{NO}_{\mathrm{y}}$ observed by the ER-2 on 11 March 2000 (Davies et al., 2002). Unfortunately, denitrification was essentially complete by the time of the first invortex ER-2 flight on 20 January 2000. This restricts the conclusions which may be drawn about the timing and rate of denitrification and hence the validity of the volume-averaged nucleation rate in DLAPSE.

\subsection{Winter 1996/97}

In winter 1996/97 the polar vortex was too warm for the formation of PSCs until early January. The general development of denitrification has been described by Mann et al. (2003). The period between mid-January and early February was characterised by a shallow and disturbed NAT-supersaturated region above $500 \mathrm{~K}$, with short particle lifetimes. Consequently, vortex-mean denitrification of only $\sim 10 \%$ is predicted by DLAPSE in the January-early February period. From mid-February onwards the situation was very different, with a deep cold pool of moderately large area aligned concentrically with the vortex flow. Model NAT particles grew to mean radii of $\sim 6 \mu \mathrm{m}$ and NAT number concentrations reached $\sim 1.5 \times 10^{-4} \mathrm{~cm}^{-3}$, causing rapid denitrification over a smaller area of the vortex $\left(\sim 9\right.$ million $\mathrm{km}^{2}$ compared with $>14$ million $\mathrm{km}^{2}$ in winter 1999/2000). Vortex mean denitrification at $450 \mathrm{~K}$ in the model reached $\sim 40 \%$ by the end of February 1997, which is considerably lower than the 66\% calculated for 1999/2000 (Mann et al., 2003). 


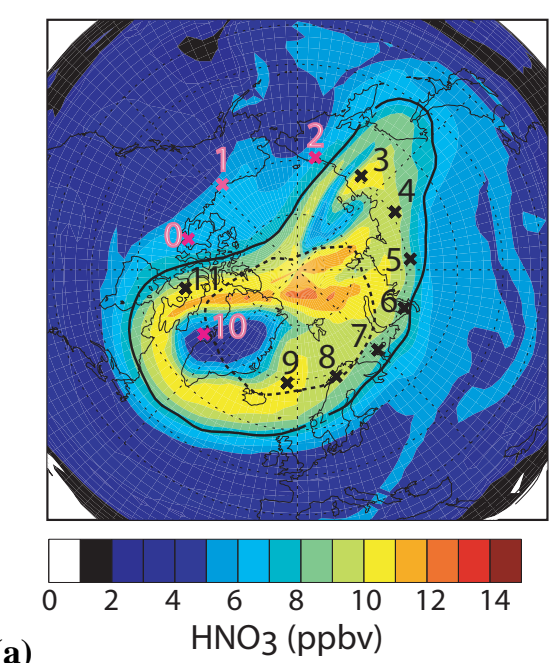

(a)

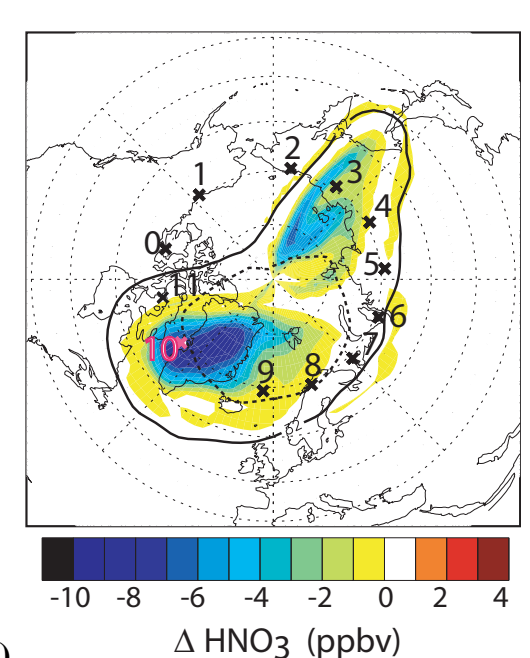

(b)

Fig. 9. DLAPSE/SLIMCAT (a) gas-phase $\mathrm{HNO}_{3}$ and (b) gas-phase $\mathrm{HNO}_{3}$-passive $\mathrm{HNO}_{3}$ at $465 \mathrm{~K}$ on 21 February 1997 . The $\mathrm{MPV}=32$ PVU contour (solid line) and $\mathrm{T}=\mathrm{T}_{\mathrm{NAT}}$ (dashed line) are also shown. The numbers denote the locations of the ILAS occultations on this day.

\subsubsection{Comparison with ILAS}

Model denitrification was compared with Version 5.20 observations from the Improved Limb Atmospheric Spectrometer (ILAS) on-board the Advanced Earth Observing Satellite (ADEOS) (Sasano et al., 1999; Sasano, 2002). Vertical distributions of measured atmospheric components (including $\mathrm{HNO}_{3}, \mathrm{O}_{3}, \mathrm{~N}_{2} \mathrm{O}$ and aerosol extinction coefficient) were obtained by constant solar tracking. The mode of operation of the ILAS instrument, in conjunction with a satellite orbit period of approximately $100 \mathrm{~min}$, combine to produce, at most, 14 daily profiles of the atmosphere in a narrow latitude band in both hemispheres e.g. 67-70 $\mathrm{N}$ for February 1997. Solar occultation instruments such as ILAS may not sample the vortex in a representative manner as the tangent points often lie close to the edge of the vortex, especially during periods of low planetary wave activity.

Model $\mathrm{NO}_{\mathrm{y}}$ was initialised from a multi-annual SLIMCAT run and constrained using ILAS $\mathrm{HNO}_{3}$ observations on 4 January 1997. Model $\mathrm{HNO}_{3}$ was interpolated to the location of the ILAS observations and scaled to fit using in-vortex and extra-vortex profiles, assuming a modified potential vorticity $\mathrm{MPV}_{465}$ of $32 \mathrm{PVU}$ at the vortex edge.

Figure 9 shows model $\mathrm{HNO}_{3}$ and denitrification at $465 \mathrm{~K}$ on 21 February 1997. The 32 PVU contours, the region of NAT-supersaturation, and the locations of the ILAS retrievals are also indicated. On this day, the polar vortex is elongated in a characteristic wave-1 pattern. There are two distinct regions of low model $\mathrm{HNO}_{3}$ corresponding to denitrification within the vortex. There is a large region with $\mathrm{HNO}_{3}$ $\sim 3$ ppbv ( $\sim 8$ ppbv denitrification) over Greenland, and an elongated region with weaker denitrification $(\sim 4 \mathrm{ppbv})$ over Arctic Russia.
In order to compare the model with ILAS observations within the polar vortex, the model output for 12:00 UT each day was spatially and temporally interpolated to each satellite profile. Comparisons of model and ILAS observations have only been made using profiles in which the aerosol extinction coefficient at $780 \mathrm{~nm}$ is less than the background value plus 3 standard deviations. This method is in accordance with that of Kondo et al. (2000) to avoid potential interference of PSCs on the retrieved profiles. ILAS $\mathrm{N}_{2} \mathrm{O}$ was used to derive $\mathrm{NO}_{\mathrm{y}}^{*}$ (Sugita et al., 1998) according to:

$\left[\mathrm{NO}_{\mathrm{y}}^{*}\right]=5.71-2.28 \chi+11.8 \chi^{2}-2.14 \chi^{3}-1.04 \chi^{4}$

where $\chi=\log _{10}\left(\left[\mathrm{~N}_{2} \mathrm{O}\right]\right.$ (ppbv)) and is valid in the range 20 ppbv $\leq\left[\mathrm{N}_{2} \mathrm{O}\right] \leq 220$ ppbv.

Comparisons of denitrification are limited to the region below $520 \mathrm{~K}$ where the $\mathrm{NO}_{\mathrm{y}}^{*}$ relation is valid. Profile 10 appears to be located within the region of strong denitrification whilst profile 3 is close to a filament of moderately denitrified air. Profile 8 is included in the comparison because it is representative of the non-denitrified regions of the polar vortex.

Figure 10 shows observed and modelled $\mathrm{HNO}_{3}$, observed $\mathrm{NO}_{\mathrm{y}}^{*}$, and model passive $\mathrm{NO}_{\mathrm{y}}$ for Points 8,10 and 3 from Fig. 9. Model profiles are shown both at original SLIMCAT resolution, and after the application of the ILAS weighting functions. These observations are typical of the comparisons between DLAPSE and ILAS in this period.

There is reasonable agreement between ILAS $\mathrm{NO}_{\mathrm{y}}^{*}$ and model passive $\mathrm{NO}_{\mathrm{y}}$, although there is a low bias of $2 \mathrm{ppbv}$ in model passive $\mathrm{NO}_{\mathrm{y}}$ below $500 \mathrm{~K}$ at Point 10. ILAS and model $\mathrm{HNO}_{3}$ are in excellent agreement for highly denitrified Point 10 and non-denitrifed Point 8 . The model overestimates $\mathrm{HNO}_{3}$ by around 3 ppbv for Point 3 , which is close to a model denitrification filament. Both model and ILAS 

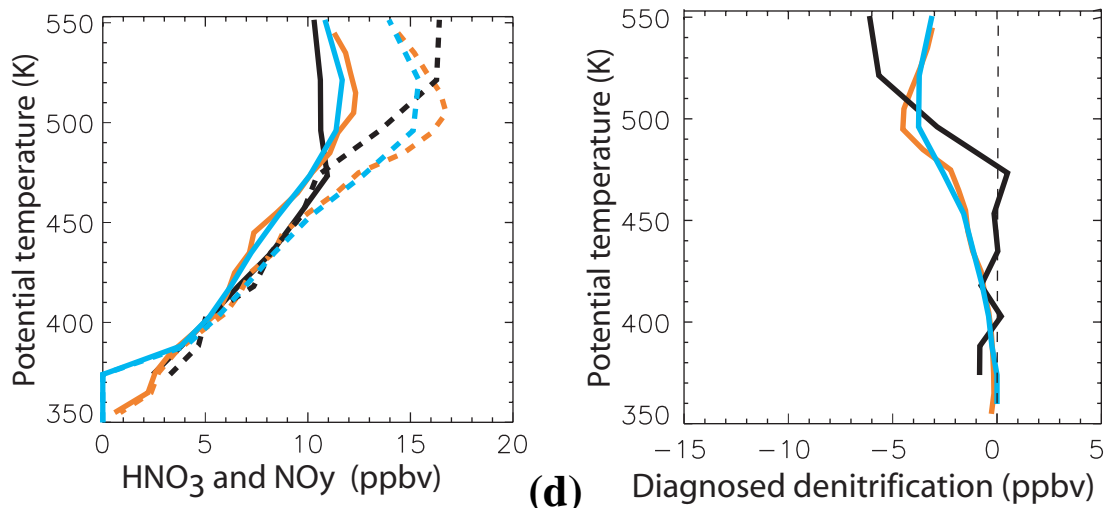

(a)

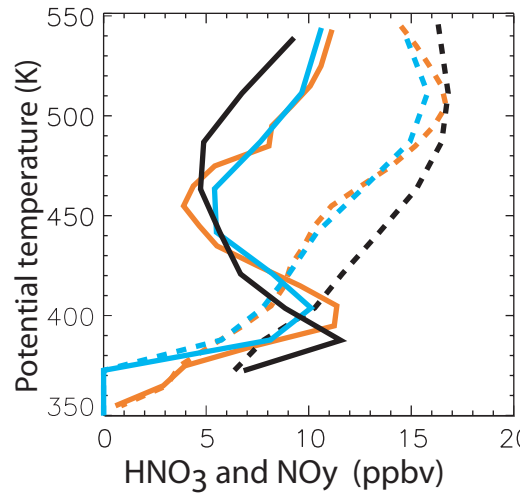

(b)

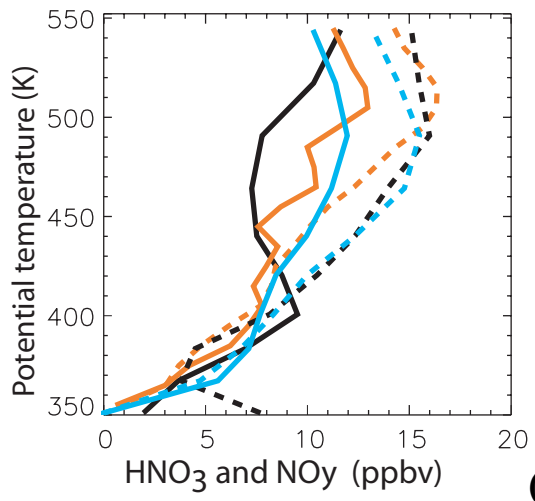

(d)

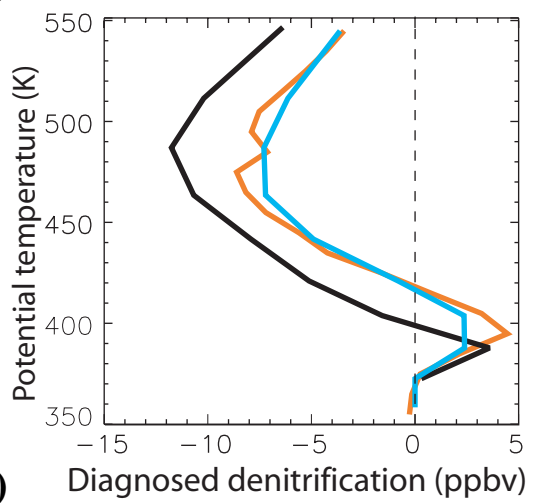

(e)

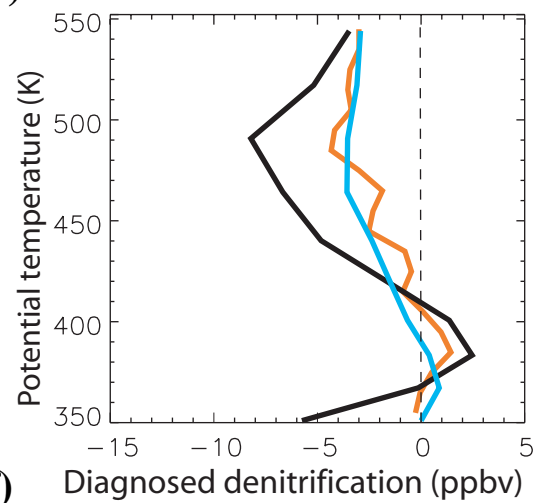

Fig. 10. (a-c) Comparison between ILAS $\mathrm{HNO}_{3}$ (solid black), ILAS NO (dashed red) at Points 8,10 and 3 respectively from Fig. 9. Also shown is model $\mathrm{HNO}_{3}$ (solid blue) and model passive $\mathrm{NO}_{\mathrm{y}}$ (dashed blue) after application of the ILAS weighting functions. (d-f) Comparison of diagnosed denitrification corresponding to (a-c) from ILAS (black), model (red) and ILAS-weighted model (blue).

$\mathrm{HNO}_{3} \approx \mathrm{NO}_{\mathrm{y}}^{*}$ below $475 \mathrm{~K}$ at Point 8 , suggesting that the vortex is highly chemically processed with low $\mathrm{ClONO}_{2}$.

The diagnosed denitrification for each of the 3 points is shown in Figs. $10 \mathrm{~d}-\mathrm{f}$. $\mathrm{NO}_{\mathrm{y}}^{*}-\mathrm{HNO}_{3}$ is used as a proxy for denitrification from the ILAS data and is compared with model passive $\mathrm{NO}_{\mathrm{y}}$-gas-phase $\mathrm{HNO}_{3}$. This approach will overestimate the magnitude of denitrification when a significant fraction of $\mathrm{NO}_{\mathrm{y}}$ in the sampled airmass is in forms other than $\mathrm{HNO}_{3}$. In this study, the greatest discrepancy between modelled and observed denitrification is likely at altitudes above $500 \mathrm{~K}$ and close to the vortex edge. The useful vertical range of this comparison is restricted to the region below $530 \mathrm{~K}$.
The model underestimates the magnitude of the maximum denitrification at Point $10(\sim 12 \mathrm{ppbv})$ by around 2 ppbv using this technique. Observed weak nitrification at $385 \mathrm{~K}$ is also captured by the model at this location. In contrast, the model significantly underestimates the observed denitrification at Point 3, although a small spatial shift could account for a significant fraction of the discrepancy due to the complex spatial structure of denitrification in the region of this observation point.

Figure 11 shows a 5-day timeseries of denitrification from both the ILAS observations and DLAPSE. Modelled denitrification is diagnosed from $\mathrm{HNO}_{3}$-passive $\mathrm{NO}_{\mathrm{y}}$, whilst ILAS 

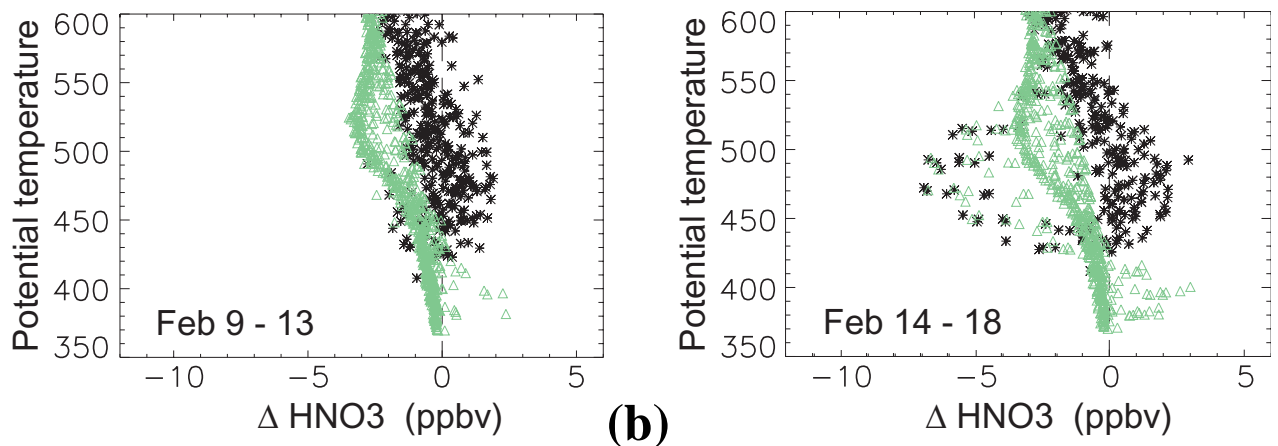

(a)

(b)
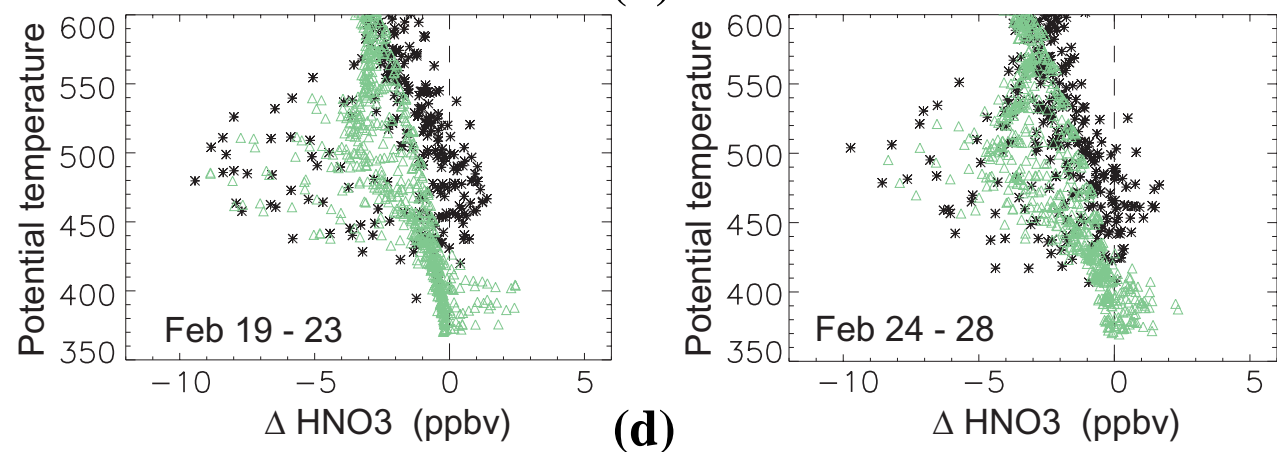

(b)

$\triangle \mathrm{HNO}(\mathrm{ppbv}) \quad$ (d)

Fig. 11. Composite profiles of interpolated model $\mathrm{HNO}_{3}$ minus passive $\mathrm{NO}_{\mathrm{y}}$ (green triangles) and $\mathrm{ILAS} \mathrm{HNO}_{3}$ minus $\mathrm{NO}_{\mathrm{y}}^{*}$ for four 5 -day periods during the 1996/97 Arctic winter.

denitrification is diagnosed as in Fig. 10. At altitudes above $470 \mathrm{~K}$, there is a systematic offset between model $\mathrm{HNO}_{3}$ and passive $\mathrm{NO}_{\mathrm{y}} \cdot \mathrm{NO}_{\mathrm{y}}$ partitioning accounts for an increasing proportion of this discrepancy with increased altitude. Preexisting weak denitrification of $\sim 1-2.5 \mathrm{ppbv}$ also contributes below $550 \mathrm{~K}$ which may be attributed to a short-lived model denitrification event in mid-January. Denitrification prior to 13 February is not evident in the ILAS observations although the magnitude of the denitrification event is similar to the inherent scatter in the diagnosed denitrification from ILAS (2-3 ppbv).

The first clear signals of denitrification in the ILAS data occur on 14 February 1997 when high PV vortex air extended southwards and became favourably located relative to the ILAS occultations on this day $\left(\sim 67^{\circ} \mathrm{N}\right)$. In the model, denitrification had begun a few days earlier but these airmasses were located poleward of ILAS occultations. In addition, enhanced aerosol extinction in sampled airmasses during the denitrification phase is another potential factor which may limit the accurate diagnosis of the timing of denitrification as both are favoured by low temperatures. The magnitude of denitrification increases rapidly in ILAS although the limitations of the $\mathrm{NO}_{\mathrm{y}}=\mathrm{HNO}_{3}$ assumption make accurate quantification difficult.

Throughout the period 14-28 February, when denitrification is evident in the ILAS observations, the model tends to underestimate the magnitude of denitrification (by 12 ppbv). The vertical extent of modelled denitrification is also slightly underestimated. The timing of the observed denitrification is consistent with modelled NAT particle growth, although the model produced earlier denitrification in airmasses which were not sampled by ILAS. In contrast, Kondo et al. (2000) have proposed that observations of denitrification diagnosed from ILAS $\mathrm{HNO}_{3}$ observations in February 1997 were consistent with particle nucleation at temperatures below $\mathrm{T}_{\text {ice }}$ along isentropic back trajectories. Ice particle formation was assumed to occur $1.5 \mathrm{~K}$ below $\mathrm{T}_{\text {ice }}$ to account for potential biases in the ECMWF analysed temperatures. Our model simulations show that denitrification in the 1996/97 winter could equally well be explained by sedimentation of low concentrations of NAT. The limited spatial and temporal range of the observations in the critical period of mid-February do not provide a strong constraint on the rate or timing of denitrification in our model.

There were MLS observations of the Arctic polar vortex on a few days in late-February, 1997. The regions of low $\mathrm{HNO}_{3}$ in the MLS observations on these days were below $\mathrm{T}_{\mathrm{NAT}}$ and could be due to temporary uptake into PSCs, denitrification or a combination of both processes. No evidence of suppressed $\mathrm{HNO}_{3}$ was observed by MLS during the following north-looking period in early April, indicating that low $\mathrm{HNO}_{3}$ mixing ratios in February were most likely due to temporary uptake into PSCs rather than denitrification (Santee et al., 2000). In contrast, low in-vortex $\mathrm{HNO}_{3}$ in DLAPSE during late-February was due mainly to denitrification (not shown). 

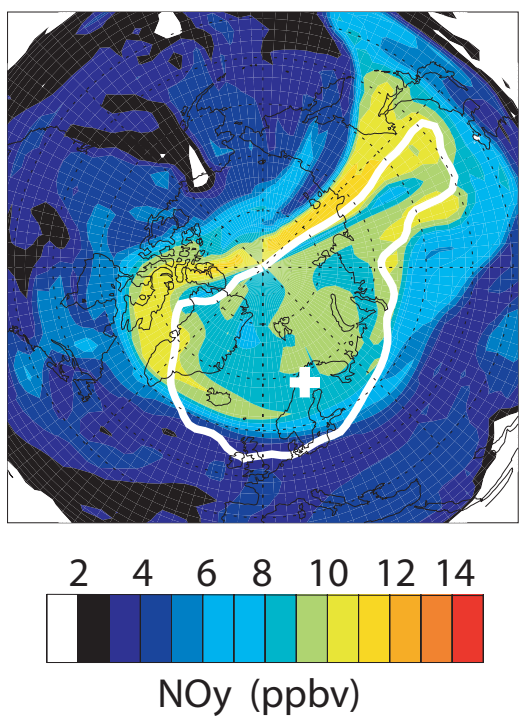

(a)

NOy (ppbv)
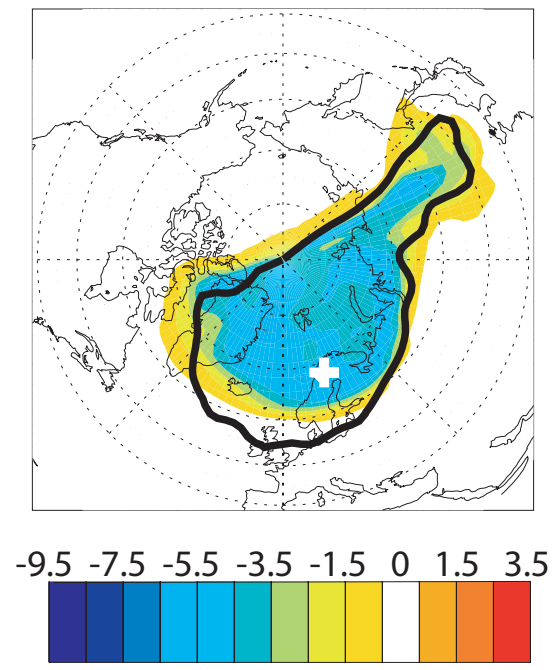

(b)

$\Delta$ NOy (ppbv)

Fig. 12. DLAPSE/SLIMCAT (a) gas-phase $\mathrm{NO}_{\mathrm{y}}$ and (b) gas-phase $\mathrm{NO}_{\mathrm{y}}$-passive $\mathrm{NO}_{\mathrm{y}}$ at $465 \mathrm{~K}$ on 11 February 1995 . The MPV=32 PVU contour is also indicated. The cross indicates the location of the MIPAS balloon launch site.

Quantification of denitrification from remote observations of gas-phase $\mathrm{HNO}_{3}$ and $\mathrm{N}_{2} \mathrm{O}$ require assumptions to be made about the partitioning of $\mathrm{NO}_{\mathrm{y}}$ in the polar stratosphere. The assumption that $\mathrm{HNO}_{3}=\mathrm{NO}_{\mathrm{y}}$ (or some large fraction of $\mathrm{NO}_{\mathrm{y}}$ ) is approximately valid in the polar lower stratosphere in early spring when $\mathrm{HNO}_{3}$ photolysis is slow and the air is often highly processed by polar stratospheric clouds. Observations with a limited latitudinal sampling range may also restrict the degree of certainty with which conclusions may be drawn on the timing of denitrification. ILAS $\mathrm{HNO}_{3}$ retrievals are only slightly affected by the presence of PSCs in the line of sight but ILAS $\mathrm{N}_{2} \mathrm{O}$ retrievals are more sensitive to the presence of PSCs (Yokota et al., 2002). The absence of usable $\mathrm{N}_{2} \mathrm{O}$ in regions of enhanced aerosol are a significant limitation to diagnosis of timing and rate of denitrification when PSCs are present. Within these constraints, the comparisons between modelled and observed denitrification demonstrate agreement, both in the spatial extent and timing of denitrification below $500 \mathrm{~K}$ when a simple volume-averaged NATparticle nucleation mechanism is used.

\subsection{Winter 1994/95}

The Arctic winter of 1994/95 was characterised by a smaller cold pool in terms of both area $\left(\sim 9\right.$ million $\left.\mathrm{km}^{2}\right)$ and vertical extent (400-550 K) when compared with 1999/2000 (Mann et al., 2003). In addition, the vortex and cold pool were generally less concentric (more baroclinic) in 1994/95. There were two short periods during 1994/95 (13-20 December and 10-15 January) when the relative orientation of the cold pool and vortex were conducive to long particle growth times and significant denitrification. Observations are available for
11 February 1995 from the Balloon-borne Michelsen Interferometer for Passive Atmospheric Sounding (MIPAS-B) instrument.

Model $\mathrm{NO}_{\mathrm{y}}$ was initialised using a mid-latitude balloon $\mathrm{NO}_{\mathrm{y}} / \mathrm{N}_{2} \mathrm{O}$ correlation (Kondo et al., 1996) from 12 October 1994. Initial model $\mathrm{NO}_{y}$ and $\mathrm{N}_{2} \mathrm{O}$ were interpolated to the latitude, longitude and altitude of the balloon observations and an observed $\mathrm{NO}_{\mathrm{y}} /$ model $\mathrm{N}_{2} \mathrm{O}$ derived for this location. This relation was then used to scale all SLIMCAT $\mathrm{NO}_{\mathrm{y}}$ throughout the northern hemisphere by adjustment of the model $\mathrm{HNO}_{3}$ tracer.

\subsubsection{Comparison with MIPAS-B}

Figure 12 shows modelled $\mathrm{NO}_{\mathrm{y}}$ and denitrification at $465 \mathrm{~K}$ on 11 February 1995. The modelled vortex is characterised by relatively low $\mathrm{NO}_{\mathrm{y}}(\sim 9 \mathrm{ppbv})$ due to widespread moderate denitrification $(\sim 4-5 \mathrm{ppbv})$ which occurred primarily in the mid-December period (Mann et al., 2003). On this date the location of the balloon launch (Kiruna, Sweden, $68^{\circ} \mathrm{N}$, $22^{\circ} \mathrm{E}$ ) was deep within the polar vortex.

Figure 13 compares $\mathrm{NO}_{\mathrm{y}}$ and $\mathrm{NO}_{\mathrm{y}}^{*}$ observations with $\mathrm{NO}_{\mathrm{y}}$ and passive $\mathrm{NO}_{\mathrm{y}}$ from DLAPSE at $465 \mathrm{~K}$ on 11 February 1995. In addition, the model output is shown interpolated to MIPAS-B sampling altitudes with a $3 \mathrm{~km}$ boxcar smoothing applied to more accurately reflect the vertical resolution of the MIPAS-B instrument. Passive $\mathrm{NO}_{\mathrm{y}}$ and observed $\mathrm{NO}_{\mathrm{y}}^{*}$ agree reasonably, especially below $23 \mathrm{~km}$ when the model output is smoothed. There are considerable discrepancies between modelled and observed $\mathrm{NO}_{\mathrm{y}}$, especially above $18 \mathrm{~km}$. This is illustrated in Fig. 13b, which compares the MIPAS-B diagnosed denitrification $\left(\mathrm{NO}_{\mathrm{y}}^{*}-\mathrm{NO}_{\mathrm{y}}\right)$ 

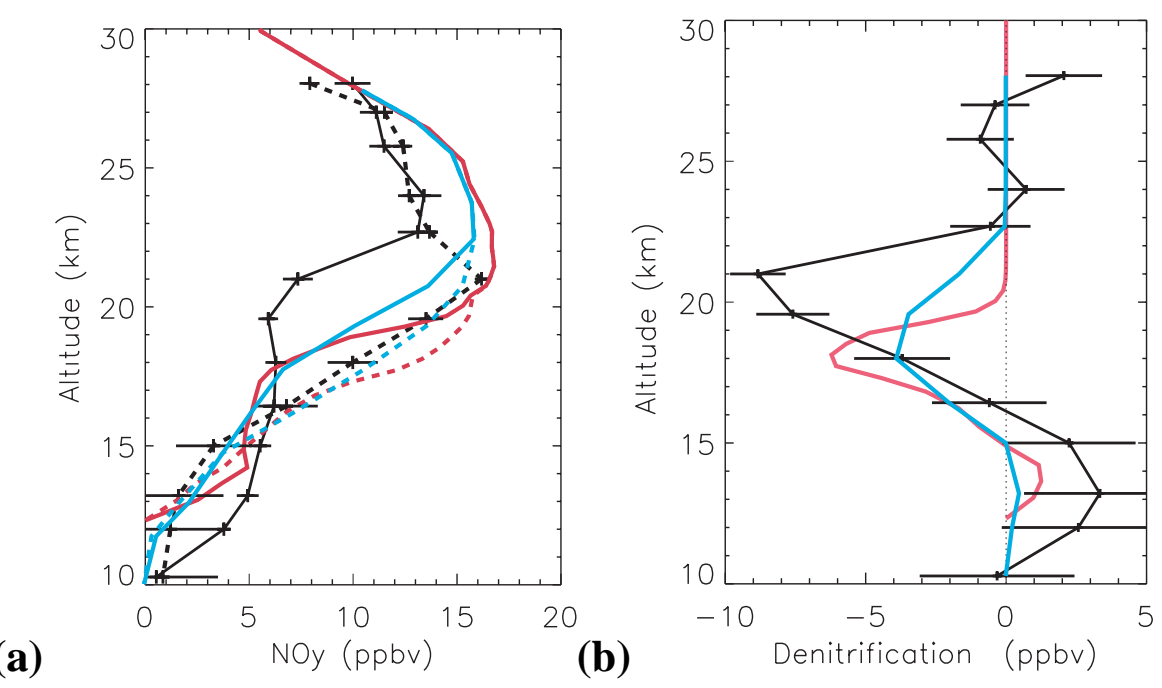

Fig. 13. (a) Comparison of MIPAS-B observed $\mathrm{NO}_{\mathrm{y}}$ (black) and $\mathrm{NO}_{\mathrm{y}}^{*}$ (dashed black) with DLAPSE/SLIMCAT NO and model passive $\mathrm{NO}_{\mathrm{y}}$ on 11 February 1995. Pairs of (a) MIPAS-B NOy (black), MIPAS-B NO* (dashed black), model NOy (red) and model passive NOy (dashed red) shown. Blue lines indicate model degraded to $3 \mathrm{~km}$ vertical resolution; (b) The diagnosed denitrification from (a).

Table 1. Model sensitivity experiments.

\begin{tabular}{lccc}
\hline Simulation & $\mathrm{S} 1$ & $\mathrm{~S} 2$ & $\mathrm{~S} 3$ \\
\hline Nucleation rate $\left(10^{-10} \mathrm{~cm}^{-3} \mathrm{~s}^{-1}\right)$ & 32.0 & 8.0 & 32.0 \\
Temperature perturbation $(\mathrm{K})$ & 0.0 & 1.5 & 1.5 \\
\hline
\end{tabular}

with modelled denitrification (passive $\mathrm{NO}_{\mathrm{y}}-\mathrm{NO}_{\mathrm{y}}$ ). Peak denitrification of $\sim 9 \mathrm{ppbv}$ occurs at $21 \mathrm{~km}$ in the observations. Both the smoothed and non-smoothed model profiles significantly underestimate the magnitude and altitude of denitrification. In addition, the magnitude of nitrification $(\sim 3 \mathrm{ppbv}$ at $13 \mathrm{~km}$ ) is also underestimated.

These results show that DLAPSE significantly underpredicts the observed denitrification in this winter when the ECMWF 31-level operational analyses are used. The discrepancy could be caused by too low NAT nucleation rates or too high analysed temperatures. Knudsen (1996) demonstrated that the analysed temperatures at 50 and $30 \mathrm{hPa}$ from the ECMWF were too warm by $1.4 \mathrm{~K}$ and $1.9 \mathrm{~K}$, respectively, at temperatures around $\mathrm{T}_{\mathrm{NAT}}$ when compared with sondes for this winter, a factor which has major implications for the prediction of denitrification. In order to investigate the sensitivity of denitrification to reductions in temperature and model nucleation rate, additional model runs were performed. The DLAPSE denitrification model used for this sensitivity study was exactly as described above but, for reasons of computational efficiency, a simplified version of SLIMCAT was used. SLIMCAT was used to passively advect the DLAPSE calculated $\mathrm{NO}_{\mathrm{y}}$ and passive $\mathrm{NO}_{\mathrm{y}}$ but without chemistry. Table 1 lists the nucleation rates and temperature perturbations used for these simulations.

Figure 14a compares model and MIPAS-B denitrification from each of the sensitivity runs listed in Table 1. Figure 14b is the equivalent plot in which the model output has been smoothed by application of a $3 \mathrm{~km}$ running mean. Balloonborne temperatures were above $200 \mathrm{~K}$, indicating that the inferred denitrification is unlikely to be enhanced by condensed $\mathrm{HNO}_{3}$. The impact on denitrification of a $4 \times$ increase in the volume-average NAT-particle nucleation rate is almost identical to the effect of a global temperature reduction of $1.5 \mathrm{~K}$ at this location. However, neither increase alone is sufficient to reproduce the observed denitrification. The observations are best reproduced by a combination of both a temperature reduction of $1.5 \mathrm{~K}$ and a $4 \times$ increase in nucleation rate in this study, although a similar response could be achieved by a greater increase in particle nucleation rate. In all cases, model denitrification is displaced vertically by $\sim 2 \mathrm{~km}$ below the observed denitrification. This discrepancy may be due to a systematic vertical offset in the analysed temperatures during the winter affecting particle growth and sedimentation, errors in model diabatic descent, or poor initialisation of model $\mathrm{NO}_{\mathrm{y}}$.

\subsubsection{Comparison with MLS}

In order to investigate this anomaly between model and MIPAS-observed denitrification, comparisons were made with MLS $\mathrm{HNO}_{3}$ observations in February and March 1995. Full MLS scans of the northern hemisphere are available for 8, 14 February and from 21 February onwards, but not for the day of the MIPAS-B flight (11 February). The ECMWF operational analyses indicate that temperatures were above 

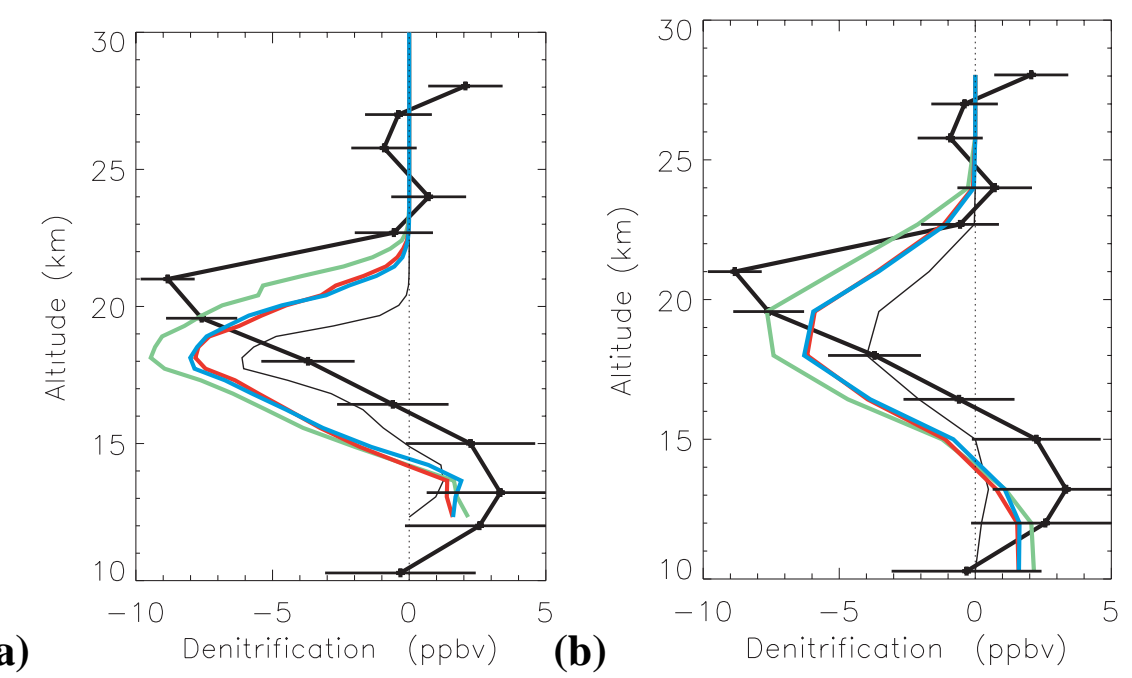

Fig. 14. Comparison of modelled and MIPAS-B observed denitrification (thick black) on (a) SLIMCAT grid, and (b) model degraded to 3 km vertical resolution for original model run (thin black line). Additional lines indicate denitrification diagnosed from the simulations listed in Table 1: S1 (red), S2 (blue) and S3 (green).

$\mathrm{T}_{\mathrm{NAT}}$ on 14 February using SLIMCAT passive $\mathrm{HNO}_{3}$ and $\mathrm{H}_{2} \mathrm{O}$.

Figure 15 compares MLS-observed $\mathrm{HNO}_{3}$ with nondenitrified and denitrified DLAPSE model. MLS seems to show relatively high ( $>10 \mathrm{ppbv}) \mathrm{HNO}_{3}$ in a semi-circular "annulus" over N Canada, Greenland to Scandinavia which is reproduced in the model. MLS clearly shows a region of suppressed $\mathrm{HNO}_{3}$ poleward of the annulus, centred on Spitzbergen $(\sim 7 \mathrm{ppbv}$ instead of $\sim 11-12 \mathrm{ppbv})$. Analysed temperatures were above $\mathrm{T}_{\mathrm{NAT}}$ on this day and, even assuming a probable warm bias of $1.5-2 \mathrm{~K}$, uptake of significant $\mathrm{HNO}_{3}$ into ternary aerosol over such a wide region seems unlikely. The passive model run (Fig. 15a) significantly overestimates $\mathrm{HNO}_{3}$ in the core of the vortex. In contrast, the denitrified run is a better fit to the observations although it still systematically overestimates the observed in-vortex $\mathrm{HNO}_{3}$.

Figure 16 and Table 2 show that the discrepancy between model and MLS $\mathrm{HNO}_{3}$ is greatest for the passive (nondenitrified) run. The discrepancy between $\mathrm{MLS} \mathrm{HNO}_{3}$ and the passive model is $\sim 5 \mathrm{ppbv}$ in the core of the vortex. Vortex-wide MLS observations of $\mathrm{HNO}_{3}$ are also overestimated by the baseline DLAPSE model run at $68 \mathrm{hPa}$ although the discrepancy is relatively small $(\sim 0.7 \mathrm{ppbv})$. The best fit to observed MLS $\mathrm{HNO}_{3}$ is achieved using either a $4 \times$ increase in the nucleation rate (model run S1) or a reduction in temperature of $1.5 \mathrm{~K}$ (model run S2). The latter is consistent with known discrepancies between the ECMWF analyses and sondes in this winter (Knudsen, 1996). The model run in best agreement with MIPAS-B (S3), overestimates the magnitude of denitrification by $\sim 0.8 \mathrm{ppbv}$ when compared with MLS. However, it is worth noting that in each of the model sensitivity runs (S1-S3), the absence of
Table 2. Mean and standard deviation of MLS - Model $\mathrm{HNO}_{3}$ for all MLS observations poleward of $65^{\circ} \mathrm{N}$ equivalent latitude on 14 February 1995. Model runs S1-S3 assume all $\mathrm{NO}_{\mathrm{y}}$ is present as $\mathrm{HNO}_{3}$. All values are in ppbv.

\begin{tabular}{lccccc}
\hline & Passive & DLAPSE & S1 & S2 & S3 \\
& & & & & \\
\hline Model - MLS & 2.44 & 0.69 & -0.11 & -0.02 & -0.71 \\
Std. dev. & 1.98 & 1.36 & 1.44 & 1.42 & 1.70 \\
\hline
\end{tabular}

a full stratospheric chemistry scheme means that the value indicated for model $\mathrm{HNO}_{3}$ is an upper limit based on the assumption that $\mathrm{HNO}_{3}=\mathrm{NO}_{\mathrm{y}}$. Comparisons between SLIMCAT/DLAPSE and MLS on the $46 \mathrm{hPa}$ pressure level (not shown) demonstrate similar agreement to that at $68 \mathrm{hPa}$. The peak in MIPAS-observed denitrification on 11 February 1995 occurs at $\sim 38 \mathrm{hPa}$, between the MLS tangent points at 32 and $46 \mathrm{hPa}$. There is no evidence of significant suppression of vortex $\mathrm{HNO}_{3}$ in either MLS or the model at $32 \mathrm{hPa}$ on 14 February.

In Waibel et al. (1999), a thermodynamic equilibrium denitrification model was used to quantitatively explain these MIPAS-B observations. Their model calculated denitrification using 3-D temperature fields but averaged the $\mathrm{HNO}_{3}$ on each isentropic level after each time step rather than transporting it as we do in our model. The model also neglected chemical reactions. NAT nucleation on ice at $\mathrm{T}_{\text {ice }}-1.5 \mathrm{~K}$ was found to best reproduce the characteristic shape and magnitude of the observed denitrification using ECMWF analyses. 

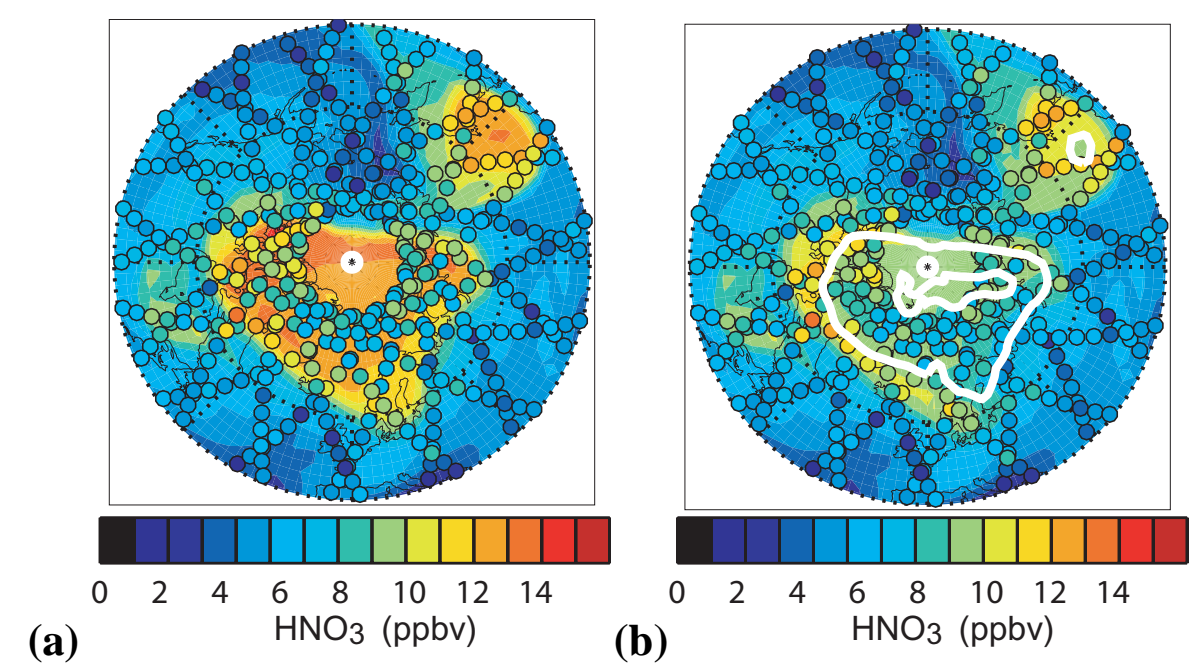

Fig. 15. Contour plot of DLAPSE/SLIMCAT (a) passive $\mathrm{HNO}_{3}$ and (b) $\mathrm{HNO}_{3}$ at $68 \mathrm{hPa}$ on 14 February 1995. Model output is smoothed using the MLS averaging kernel. Version $6 \mathrm{MLS} \mathrm{HNO}_{3}$ is also shown by the filled circles. The white contour indicates the region where smoothed model denitrification exceeds 3 ppbv.

(a)
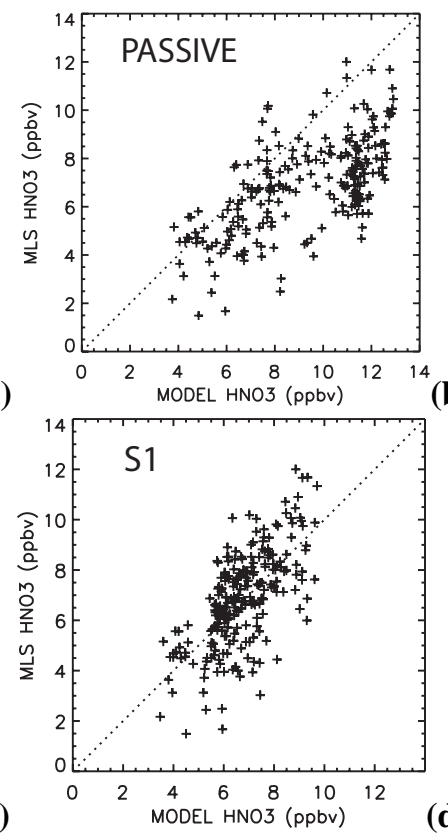

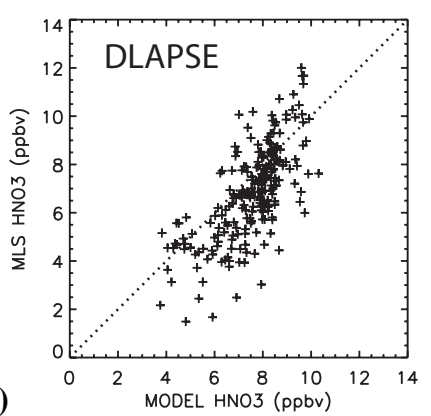

(b)

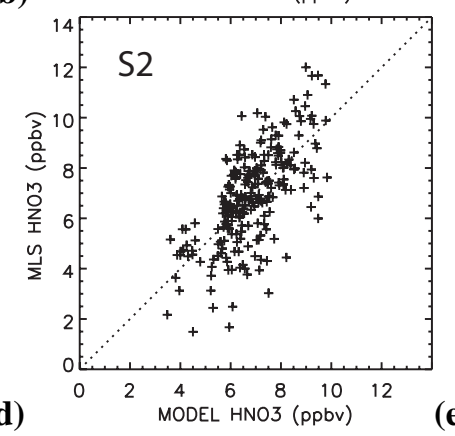

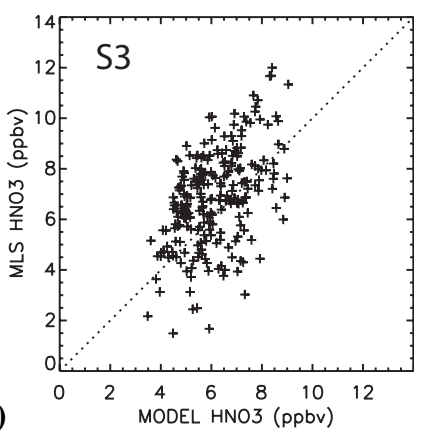

Fig. 16. Scatter plot of model and MLS observed $\mathrm{HNO}_{3}$ poleward of $65^{\circ} \mathrm{N}$ equivalent latitude for (a) passive, (b) DLAPSE, (c) run S1, (d) run S2 and (e) run S3 at $68 \mathrm{hPa}$ on 14 February 1995. Model output is spatially and temporally interpolated to MLS observations and smoothed using the MLS averaging kernel.

They rejected the possibility of NAT nucleation and sedimentation as the cause of denitrification because their model produced too much denitrification at high altitudes. This result led Waibel et al. (1999) to suggest that NAT nucleation on ice was responsible for denitrification. Our full kinetic simulation of NAT growth in a 3-D chemical transport model produces a denitrification profile that is in fair agreement with
MIPAS-B observations on 11 February and better agreement with MLS during mid-February. Based on all these comparisons, we believe it is now no longer possible to reject a NAT-only mechanism of denitrification in the 1994/95 winter.

The poor agreement between MIPAS-observed and modelled denitrification when we use NAT nucleation rates 
defined by the January 2000 observations is interesting. The poor agreement may indicate that average NAT nucleation rates were much larger (at least a factor 4) in early winter $1994 / 95$, even when a correction is made for a possible warm bias of $\sim 1.5 \mathrm{~K}$ in the ECMWF-analysed vortex temperatures through the main denitrification period in December. Sugita et al. (1998) attribute the denitrification observed by MIPAS$\mathrm{B}$ on this date to NAT nucleation in mountain wave ice clouds and subsequent NAT particle growth below $\mathrm{T}_{\mathrm{NAT}}$. This effect could contribute to the apparent discrepancy between the model and MIPAS-B denitrification on 11 February.

\section{Conclusions}

In situ and remote observations of denitrification in three recent Arctic winters (1994/95, 1996/97 and 1999/2000) have been used to evaluate the performance of DLAPSE/SLIMCAT. This novel model comprises a full-chemistry version of the Eulerian SLIMCAT CTM coupled to a semi-Lagrangian NAT-particle growth and sedimentation model (DLAPSE). NAT particle nucleation in DLAPSE was constrained by observations of large NAT particle populations from the $\mathrm{NO}_{\mathrm{y}}$ instrument on 20 January 2000. The constant volume-average nucleation rate used in the model was $8.0 \times 10^{-10} \mathrm{~cm}^{-3} \mathrm{~s}^{-1}$.

In 1999/2000, the evolution of denitrification was observed by the ER-2 between 20 January and 12 March. The coupled model captures the temporal evolution of denitrification in this period. The vertical distribution of denitrification and nitrification was consistent with ER-2 observations although quantitative diagnosis requires accurate initialisation and transport of the model passive $\mathrm{NO}_{\mathrm{y}}$ tracer.

Comparisons with remote ILAS observations during the Arctic winter of 1996/97 demonstrate that the model captures both the spatial extent and timing of observed denitrification. The first clear observations of denitrification on 14 February occurred when the vortex core was sufficiently displaced to the lower latitudes sampled by ILAS. Model denitrification began in the closed flow region at the core of the vortex around 1 week prior to these first observations of denitrification in airmasses which were not sampled by ILAS. The lack of observations poleward of $\sim 67^{\circ} \mathrm{N}$ from ILAS during the critical initial denitrification phase is a limitation on further constraining NAT particle nucleation mechanisms.

The limited number of $\mathrm{NO}_{\mathrm{y}}$ species observed by ILAS requires assumptions to be made about the partitioning of $\mathrm{NO}_{\mathrm{y}}$ in the sampled air masses before quantification of the magnitude of observed denitrification is possible. It is likely that the model underestimates observed denitrification by $\sim 1-$ 2 ppbv although this discrepancy is of similar magnitude to likely errors in assumptions of the partitioning of $\mathrm{NO}_{\mathrm{y}}$ in the highly processed vortex below $500 \mathrm{~K}$.

Significantly greater discrepancies are apparent when comparisons are made between DLAPSE and MIPAS-B ob- servations of denitrification on 11 February 1995. It is likely that a warm bias in the ECMWF analysed temperatures of at least $1.5 \mathrm{~K}$ is partly responsible for this discrepancy. Sensitivity studies indicate that a four-fold increase in the nucleation rate together with a reduction in temperature of $1.5 \mathrm{~K}$ are necessary to reproduce the observations of denitrification. Additional denitrification from mountain wave iceinduced NAT "mother clouds" would be expected to contribute to denitrification (Fueglistaler et al., 2002; Dhaniyala et al., 2002). It is possible that such mother clouds may be sufficiently numerous to seed large regions of the Arctic vortex with sufficient NAT particles to cause efficient denitrification (Mann et al., 2005), although it is important not to over-interpret a discrepancy between DLAPSE and a single denitrification profile. Model comparisons with $\mathrm{MLS} \mathrm{HNO}_{3}$ on 2 days in mid-February show much better agreement, especially when a temperature reduction of $1.5 \mathrm{~K}$ is applied to the model or the nucleation rate is increased by a factor of 4 .

In summary, the simple constant volume average NAT nucleation scheme in DLAPSE/SLIMCAT is able to reproduce many aspects of observed denitrification from a variety of platforms over three recent winters. However, there appears to be additional inter-annual variability in the magnitude of denitrification that is not captured by the model. The differences between the modelled and observed denitrification in any one winter can be improved by straightforward adjustments to the assumed rate of NAT formation. However, further work should focus on identifying the physical processes causing NAT formation, leading to appropriate rates that can be included in large-scale models.

The absence of frequent, high-resolution $\mathrm{NO}_{\mathrm{y}}$ and aerosol measurements throughout the Arctic vortex places significant limitations on the initialisation of model $\mathrm{NO}_{\mathrm{y}}$ fields. High resolution $\mathrm{NO}_{\mathrm{y}}$ observations would prove invaluable for unambiguously diagnosing the timing and extent of denitrification, which would aid testing NAT nucleation mechanisms. New data from the next generation of satellites (ENVISAT, SAGE III and Aura) should provide valuable additional $\mathrm{NO}_{\mathrm{y}}$ and PSC data to aid this process.

Acknowledgements. This work was supported by the European Commission Framework 5 projects EUPLEX and MAPSCORE under contracts EVK2-CT-2002-00084 and EVK2-CT-2000-00072 and by the Framework 6 project SCOUT. S. Davies thanks the UK Natural Environment Research Council for funding his PhD studentship. The authors acknowledge the contribution of D. W. Fahey (NOAA), G. C. Toon (NASA JPL) and H.-J. Jost (NASA Ames) in providing the $\mathrm{NO}_{\mathrm{y}}$ and $\mathrm{N}_{2} \mathrm{O}$ data used to evaluate the model in 1999/2000. Work at the Jet Propulsion Laboratory, California Institute of Technology, was done under contract with the National Aeronautics and Space Administration.

Edited by: M. Dameris 


\section{References}

Arnold, F., Bürger, V., Gollinger, K., Roncossek, M., Schneider, J., and Spreng, S.: Evidence for stratospheric nitric acid condensation from balloon and rocket measurements, Nature, 342, 493-497, 1989.

Carslaw, K. S., Luo, B. P., and Peter, T.: An analytic expression for the composition of aqueous $\mathrm{HNO}_{3}-\mathrm{H}_{2} \mathrm{SO}_{4}$ stratospheric aerosols including gas-phase removal of $\mathrm{HNO}_{3}$, Geophys. Res. Lett., 22, 1877-1880, 1995.

Carslaw, K. S., Peter, T., and Clegg, S. L.: Modeling the composition of liquid stratospheric aerosols, Rev. Geophys., 35, 125-154, 1997.

Carslaw, K. S., Wirth, M., Tsias, A., Luo, B. P., Dörnbrack, A., Leutbecher, M., Volkert, H., Renger, W., Bacmeister, J. T., and Peter, T.: Increased stratospheric ozone depletion due to mountain wave induced atmospheric waves, Nature, 391, 675-678 , 1998.

Carslaw, K. S., Peter, T., Backmeister, J. T., and Eckermann, S. D.: Widespread solid particle formation by mountain waves in the Arctic stratosphere, J. Geophys. Res., 104, 1827-1836, 1999.

Carslaw, K. S., Kettleborough, J., Northway, M. J., Davies, S., Gao, R.-S., Fahey, D. W., Baumgardner, D. G., Chipperfield, M. P., and Kleinböhl, A.: A vortex-scale simulation of the growth and sedimentation of large nitric acid hydrate particles, J. Geophys. Res., 107, doi:10.1029/2001JD000467, 2002.

Chipperfield, M. P.: Multiannual simulations with a three- dimensional chemical transport model, J. Geophys. Res., 104, 17811805, 1999.

Davies, S. Chipperfield, M. P., Carslaw, K. S., Sinnhuber, B.-M., Anderson, J. G., Stimpfle, R. M., Wilmouth, D. M., Fahey, D. W., Popp, P. J., Richard, E. C., von der Gathen, P., Jost, H., and Webster, C. R.: Modeling the effect of denitrification on Arctic ozone depletion during winter 1999/2000, J. Geophys. Res., 107, 8322, doi:10.1029/2001JD000445, 2002.

Deshler, T., Peter, T., Müller, R., and Crutzen, P.: The lifetime of leewave-induced ice particles in the Arctic stratosphere: 1 . Balloonborne observations, Geophys. Res. Lett., 21, 1327-1330, 1994.

Deshler, T. and Oltmans, S. J.: Vertical profiles of volcanic aerosol and polar stratospheric clouds over Kiruna, Sweden, winters 1993 and 1995, J. Atmos. Chem., 30, 11-23, 1998.

Dessler, A. E., Wu, J., Santee, M. L., and Schoeberl, M. R.: Satellite observations of temporary and irreversible denitrification, J. Geophys. Res., 104, 13993-14002, 1999.

Dhaniyala, S., McKinney, K., and Wennberg, P. O.: Lee-wave clouds and denitrification of the polar stratosphere, Geophys. Res. Lett., 29, doi:10.1029/2001GL013900, 2002.

Drdla, K., Schoeberl, M. R., and Rosenfeld, J.: Microphysical modeling of the 1999/2000 Arctic winter. 1. Polar stratospheric clouds, denitrification and dehydration, J. Geophys. Res., 107, doi:10.1029/2001JD001159, 2002.

Fahey, D. W., Kelly, K. K., Kawa, S. R., Tuck, A. F., Lowenstein, M., Chan, K. R., and Heidt, L. E.: Observations of denitrification and dehydration in the winter polar stratospheres, Nature, 344, 321-324, 1990.

Fahey, D. W., Gao, R.-S., Carslaw, K. S., Kettleborough, J., Popp, P. J., Northway, M. J., Holecek, J. C., Ciciora, S. C., R. J. McLauchlin, Thompson, T. L, Winkler, R. H., Baumgardner, D. G., Gandrud, B., Wennberg, P. O., Dhaniyala, S.,McKinney, K., Peter,
T., Salawitch, R. J., Bui, T. P., Elkins, J. W., Webster, C. R., Atlas, E. L., Jost, H., Wilson, J. C., Herman, R. L., Kleinböhl, A., and von Koenig, M.: The detection of large $\mathrm{HNO}_{3}$-containing particle in the winter Arctic stratosphere and their role in denitrification, Science, 291, 1026-1031, 2001.

Fromm, M., Alfred, J., and Pitts, M.: A unified, long-term, high-latitude stratospheric aerosol and cloud database using SAMII, SAGEII and POAMII/III data: Algorithm description, database definition and climatology, J. Geophys. Res., 108, 4366, doi:10.1029/2002JD002772, 2003.

Fueglistaler, S., Luo, B. P., Voigt, C., Carslaw, K. S., and Peter, T.: NAT-rock formation by mother clouds: a microphysical model study, Atmos. Chem. Phys., 2, 93-98, 2002,

SRef-ID: 1680-7324/acp/2002-2-93.

Fueglistaler, S., Buss, S., Luo, B. P., Wernli, H., Flentje, H., Hostetler, C., Poole, L. R., Carslaw, K. S., and Peter, T.: Detailed modeling of mountain wave PSCs, Atmos. Chem. Phys., 3, 697-712, 2003 ,

SRef-ID: 1680-7324/acp/2003-3-697.

Greenblatt, J. B., Jost, H., Loewenstein, M., Podolske, J. R., et al.: Tracer-based determination of vortex descent in the 199-2000 Arctic winter, J. Geophys. Res., 107, 8279, doi:10.1029/2001JD000937, 2002.

Hu, R.-M., Carslaw, K. S., Hostetler, C., Poole, L. R., Luo, B. P., Peter, Th., Fueglistaler, S., McGee, J., and Burris, J. F.: Microphysical properties of wave polar stratospheric clouds retrieved from lidar measurements during SOLVE/THESEO 2000, J. Geophys. Res., 107, 8294, doi:10.1029/2001JD001125, 2002.

Jost, H., Loewenstein, M., Pfister, L., Margitan, J. J., Chang, A. Y., Salawitch, R. J., and Michelsen, H. A., Laminae in the tropical middle stratosphere: Origin and age estimation, Geophys. Res. Lett., 25, 4337-4340, 1998.

Knopf, D. A., Koop, T., Luo, B. P., Weers, U. G., and Peter, T.: Homogeneous nucleation of NAD and NAT in liquid stratospheric aerosols: insufficient to explain denitrification, Atmos. Chem. Phys., 2, 207-214, 2002,

SRef-ID: 1680-7324/acp/2002-2-207.

Knudsen, B. M.: Accuracy of arctic stratospheric temperature analyses and the implications for the prediction of polar stratospheric clouds, Geophys. Res. Lett., 23, 3747-3750, 1996.

Kondo, Y., Schmidt, U., Sugita, T., Engel, A., Koike, M., Aimedieu, P., Gunson, M. R., and Rodriguez, J.: $\mathrm{NO}_{\mathrm{y}}$ correlation with $\mathrm{N}_{2} \mathrm{O}$ and $\mathrm{CH}_{4}$ in the midlatitude stratosphere, Geophys. Res. Lett., 23, 2369-2372, 1996.

Kondo, Y., Irie, H., Koike, M., and Bodecker, G. E.: Denitrification and nitrification in the Arctic stratosphere during the winter of 1996/97, Geophys. Res. Lett., 27, 337-340, 2000.

Mann, G. W., Davies, S., Carslaw, K. S., Chipperfield, M. P., and Kettleborough, J.: Polar vortex concentricity as a controlling factor in Arctic denitrification, J. Geophys. Res., 107, D22, 4663, doi:10.1029/2002JD002102, 2002.

Mann, G. W., Davies, S., Carslaw, K. S., and Chipperfield, M. P. Factors controlling Arctic denitrification in cold winters of the 1990s, Atmos. Chem. Phys., 3, 403-416, 2003, SRef-ID: 1680-7324/acp/2003-3-403.

Mann, G. W., Carslaw, K. S., Chipperfield, M. P., Davies, S., and Eckermann, S. D.: Large NAT particles and denitrification caused by mountain waves in the Arctic stratosphere, J. Geophys. Res., 110, D08202 doi:10.1029/2004JD005271, 2005. 
Meilinger, S. K., Koop, T., Luo, B. P., Huthwelker, T., Carslaw, K. S., Kreiger, U., Crutzen, P. J., and Peter, T.: Size-dependent stratospheric droplet composition in mesoscale temperature fluctuations and their potential role in PSC freezing, Geophys. Res. Lett., 22, 3031-3034, 1995.

Müller, R. and Peter, T.: The numerical modelling of the sedimentation of polar stratospheric clouds, Ber. Bunsenges. Phys. Chem., 96, 353-361, 1992.

Northway, M. J., Gao, R.-S., Popp, P. J., Holecek, J. C., Fahey, D. W., Carslaw, K. S. Tolbert, M. A., Lait, L. R., Dhaniyala, S., Flanagan, R. C., Wennberg, P. O., Mahoney, M. J., Herman, R. L., Toon, G. C., and Bui, T. P.: An analysis of large $\mathrm{HNO}_{3}$-containing particels sampled in the Arctic stratosphere during the winter of 1999/2000. J. Geophys. Res., 107, 8298, doi:10.1029/2001JD001079, 2002.

Pagan, K. L., Tabazadeh, A., Drdla, K., Hervig, M. E., Eckermann, S. D., Browell, E. V., Legg, M. J., and Foschi, P. G.: Observational evidence against mountain-wave generation of ice nuclei as a prerequisite for the formation of three solid nitric acid polar stratospheric clouds observed in the Arctic in early December 1999, J. Geophys. Res., 109, doi:10.1029/2003JD003846, 2004.

Pawson, S. and Naujokat, B.: The cold winters of the middle 1990s in the northern lower stratosphere, J. Geophys. Res., 104, 14 209-14 222, 1999.

Popp, P., Northway, M. J., Holecek, J. C., Gao, R.-S., Fahey, D. W., Elkins, J. W., Hurst, D. F., Romashkin, P. A., Toon, G. C., Sen, B., Schauffler, S. M., Salawitch, R. J., Webster, C. R., Herman, R. L., Jost, H., Bui, T. P., Newman, P. A., and Lait, L. R.: Severe and extensive denitrification in the 1999-2000 Arctic winter stratosphere, Geophys. Res. Lett., 28, 2875-2878, 2001.

Salcedo, D., Molina, L. T., and Molina, M. J.: Homogeneous freezing of concentrated aqueous nitric acid solutions at polar stratospheric temperatures, J. Phys. Chem. A, 105, 1433-1439, 2001.

Saitoh, N., Hayashida, S., Sasano, Y., and Pan, L. L.: Characteristics of Arctic polar stratospheric clouds in the winter of 1996/1997 inferred from ILAS measurements,J. Geophys. Res., 107, D24, 8205, doi:10.1029/2001JD000595, 2002.

Sander, S. P., Ravishankara, A. R., Friedel, R. R., et al.: Chemical Kinetics and Photochemical Data for Use in Stratospheric Modeling. Evaluation 13, JPL Publ. 00-3, 2000.

Santee, M. L., Manney, G. L., Livsey, N. J., and Waters, J. W.: UARS Microwave Limb Sounder observations of denitrification ond ozone loss in the 2000 Arctic late winter, Geophys. Res. Lett., 27, 2313-2316., 2000.

Sasano, Y., Suzuki, M., Yokota, T., and Kanawa, H.: Improved Limb Atmospheric Spectrometer (ILAS) for stratospheric ozone layer measurements by solar occultation technique, Geophys. Res. Lett., 26, 197-200, 1999.

Sasano, Y.: Preface, J. Geophys. Res., 107, D24, 8204, doi:10.1029/2002JD002155, 2002.

Spang, R., Riese, M., and Offermann, D.: CRISTA-2 observations of the south polar vortex in winter 1997: A new dataset for polar process studies, Geophys. Res. Lett., 28, 3159-3162, 2001.
Sugita, T. Kondo, Y., Nakajima, H., Schmidt, U., Engel, A., Oelhaf, H., Wetzel, G., Koike, M., and Newman, P. A.: Denitrification observed inside the Arctic vortex in February 1995, J. Geophys. Res., 103, 16221-16223, 1998.

Tabazadeh, A., Toon, O. B., Gary, B. L., Bacmeister, J. T., and Schoeberl, M. R.: Observational constraints on the formation of type1a polar stratospheric clouds, Geophys. Res. Lett., 23, 2109 2112, 1996.

Tabazadeh, A.: Role of the stratospheric polar freezing belt in denitrification, Science, 291, 2591-2594, 2001.

Tabazadeh, A., Djikaev, Y. S., Hammill, P., and Reiss, H.: Laboratory evidence for surface nucleation of solid polar stratospheric clouds, J. Phys. Chem. A, 106, 43, 10 238-10 246, 2002.

Tabazadeh, A.: Commentary on "Homogeneous nucleation of NAD and NAT in liquid stratospheric aerosols: insufficient to explain denitrification" by Knopf et al., Atmos. Chem. Phys., 3, 863865, 2003,

SRef-ID: 1680-7324/acp/2003-3-863.

Toon, G. C., Farmer, C. B., Schaper, P. W., et al.: Evidence for subsidence in the 1989 Arctic winter stratosphere from airborne infrared composition measurements, J. Geophys. Res., 97, 79637970, 1992.

Tsias, A., Prenni, T., Carslaw, K. S., Onasch, T. P., Luo, B. P., Tolbert, M. A., and Peter, T.: Freezing of polar stratospheric clouds in orographically induced strong warming events, Geophys. Res. Lett., 24, 2303-2306, 1997.

Waibel, A. E., Peter, T., Carslaw, K. S., Oelhaf, H., Wetzel, G., Crutzen, P. J., Poschl, U., Tsias, A., Reimer, E., and Fischer, H.: Arctic ozone loss due to denitrification, Science, 283, 17561758, 1999.

Waters, J. W., Read, W. G., Froidevaux, L., et al.: The UARS and EOS Microwave Limb Sounder (MLS) experiments, J. Atmos. Sci., 56, 194-218, 1999.

Wetzel, G., Oelhaf, H., Ruhnke, R., et al.: Vertical profiles of $\mathrm{N}_{2} \mathrm{O}_{5}, \mathrm{HO}_{2} \mathrm{NO}_{2}$, and $\mathrm{NO}_{2}$ inside the Arctic vortex, retrieved from MIPAS-B2 infrared limb emission measurements in February 1995, J. Geophys. Res., 102, 19 177-19 186, 1997.

Wirth, M., Tsias, A., Dörnbrack, A., Weiss, V., Carslaw, K. S., Leutbecher, M., Renger, W., Volkert, H., and Peter, T.: Model-guided Lagrangian observation and simulation of mountain polar stratospheric clouds, J. Geophys. Res., 104, 23 917-23 981, 1999.

Yokota, T., Nakajima, H., Sugita, T., Tsubaki, H., Itou, Y., Kaji, M., Suzuki, M., Kanzawa, H., Park, J. H., and Sasano, Y.: Improved Limb Atmospheric Spectrometer (ILAS) data retrieval algorithm for Version 5.20 gas profile products, J. Geophys. Res., 107, D24, 8216, doi:10.1029/2001JD000628, 2002

Yu, F.: Formation of large NAT particles and denitrification in polar stratosphere: possible role of cosmic rays and effect of solar activity, Atmos. Chem. Phys., 4, 2273-2283, 2004,

SRef-ID: 1680-7324/acp/2004-4-2273. 